\title{
Study of in-flight particle stream and particle behavior for understanding the instability phenomenon in plasma spraying process
}

\author{
T. Liu *, J. Arnold \\ Institute of Engineering Thermodynamics, German Aerospace Center, Pfaffenwaldring 38-40, D-70569 Stuttgart, Germany
}

\section{A R T I C L E I N F O}

\section{Article history:}

Received 9 October 2015

Revised 1 December 2015

Accepted in revised form 7 December 2015

Available online 8 December 2015

\section{Keywords:}

Powder feeding instability

Plasma spraying process

Coating structure

Particle behavior

Slug description

\begin{abstract}
A B S T R A C T
For understanding the effect of powder feeding fluctuation on coating structure, in-flight particles were investigated by means of image analyzing. Particle behavior was estimated through numerical calculation on the base of force equilibrium. High definition videos were captured focusing on the in-flight particle stream and transparent carrier tube. Yttria-stabilized Zirconia (YSZ) coating was prepared with vacuum plasma spraying for clarifying the effect of powder feeding instability on coating structure. Optic micro-morphology of coating was obtained for porosity ratio estimation. An imaginary ring of bent tube was proposed for understanding particle behavior when unavoidable bends exist. Results indicate that periodic fluctuations exist in in-flight particle trajectory and in powder feeding. A transition region was found for particles with different diameters in regions between $0^{\circ}$ and $180^{\circ}$ within which particles with large sizes are difficult to transport. As a consequence, accumulation of powder was thus found both on upslope and downslope. The effective cross-section of the carrier tube for powder carrying was found reduced. According to the calculation, reducing equivalent diameter and increasing carrier gas flowrate have the same effect on powder carrying. A threshold was proposed to understand the slug behavior as: growing, maturity and breaking. Due to the break of slug, 'powder flooding' happens and may cause mutation in in-flight particle stream. Obvious increase was found in injected particle quality to induce the threelayer structure of coating. An empirical equation was proposed to describe slug behavior as a synthesis of growth rate and loss rate.
\end{abstract}

(C) 2015 Elsevier B.V. All rights reserved.

\section{Introduction}

As an efficient method for surface modification, plasma spray is widely used for industrial solution. However, the development of plasma spray process is shortened by poor reproducibility which is mainly excited by the combination of fluctuations in operating condition and in the powder feeding [1-3]. The source of fluctuation is numerous, such as the arc root, plasma gas composition, and powder feeding. These fluctuations may cause an obvious deviation in in-flight particle characteristics even with the same operating parameters. Many works were reported concerning the instability of plasma jet and particle characteristic with various diagnostic methods, such as DPV-2000, and spray-watch. Bisson et al. [1] watched variation in particle temperature and velocity with a magnitude of $600{ }^{\circ} \mathrm{C}$ and $200 \mathrm{~m} / \mathrm{s}$ respectively during one fluctuation period. Some works also show interest in the fluctuation of plasma jet. Kieschke et al. [2] observed a variation of $20 \%$ in plasma plume length $(200 \mathrm{~mm})$ with a high speed video for $1 \mathrm{~ms}$. Meanwhile, both experimental and numerical works have been developed to clarify the influence of fluctuation on coating property [3-8]. The effect of powder feeding on in-flight particle characteristic was

\footnotetext{
* Corresponding author.

E-mail address: taikai.liu@dlr.de (T. Liu).
}

also investigated; that with different injector geometries the profile of particle temperature and velocity consequently varied before impacting [9].

The flow system involved in the plasma spraying process concerns the pneumatic conveyance of gas-powder. Due to the range of powder granularity, a visible difference may exist between fine particles and coarse particles in pneumatic conveying characteristics. Therefore, significant variations in pressure can exist along the tube that will cause unstable distribution of powder to form a dilute phase and dense phase $[10,11]$. With the introduction of the bending effect of the carrier tube, the core flow will shift toward the outer wall to form compressed flow while dilute flow is found in the inner wall region [12]. Meanwhile, solid particles following the cone flow can deposit on the inner wall with different patterns depending on the carrier velocity and powder mass flowrate, e.g. annular deposition with high velocity and gravitational deposition with high mass flowrate $[13,14]$. By employing motion equation of particle, e.g. drag force and gravity, particle behavior can be clearly predicted in horizontal pipe and in vertical pipe and in bent pipe [15-17].

Unfortunately, the influence of particle behavior inside the carrier tube on coating structure is still not clear. Thus, the aim of this work is to understand the behavior of particles inside the carrier tube and clarify the effect on coating structure. The diagnostic methods employed in 
these works only considered a small volume for data acquisition with a selected stand-off position or only focused on the plasma jet. There is no a contribution on dealing with the detail of in-flight particle trajectory considering the time fluctuation and position variation. Therefore, in this work, both of the plasma jet and in-flight particle stream were observed and recorded with a speed of $30 \mathrm{fps}$ and resolution of $1280 \times 720$. Accordingly, a global view of the plasma jet and in-flight particles was obtained. With Matlab (R2009a, Mathworks, Natick, USA), video data was easily deconstructed and analyzed frame-byframe.

\section{Experimental methods}

\subsection{Operating condition}

This work was based on the experiment carried out in a VPS chamber (Fig. 1a). A F4-VB type torch (Sulzer, Metco, Wohlen, Switzerland) was employed with a XY movement motor (Fig. 1b). The internal diameter of the anode used is $6 \mathrm{~mm}$. The torch was automatically controlled at $35^{\circ} \mathrm{C}$ with a water cooling system. The internal diameter of the injector was $1.8 \mathrm{~mm}$ which was installed $3 \mathrm{~mm}$ downstream of the nozzle exit, and the out-port of the injector was aligned to the anode internal wall. The powder feeder was horizontally separated from the spray chamber with a distance of about $3 \mathrm{~m}$. The powder was transported to the injector through a carrier pipe with a length of $5 \mathrm{~m}$ along which four bends exist. The feedstock used is Yttria-stabilized-Zirconia (YSZ, $8 \mathrm{~mol} \%,\left(\mathrm{ZrO}_{2}\right)_{92}\left(\mathrm{Y}_{2} \mathrm{O}_{3}\right)_{8}$, Metco 6613$)$ with a size of $\mathrm{d}_{50}=14 \mu \mathrm{m}$ and $\mathrm{d}_{10} / \mathrm{d}_{90}=7 \mu \mathrm{m} / 23 \mu \mathrm{m}$. 304L stainless steel with a composition of 18 wt.\% $\mathrm{Cr}+2$ wt.\% $\mathrm{Mg}+8 \mathrm{wt} . \% \mathrm{Ni}+72 \mathrm{wt} . \%$ Fe was used as the substrate material. The substrate was prepared as a disk with a dimension of $\Phi 40 \mathrm{~mm} \times 5 \mathrm{~mm}$. The vacuum pump automatically pumps out the excess gas in order to keep the chamber pressure at 70 mbar. Sample was sprayed by focusing the plasma torch on the substrate center with a stand-off of $350 \mathrm{~mm}$ for $5 \mathrm{~s}$. During spraying, current intensity was always fixed at $500 \mathrm{~A}$. Flowrates of argon and hydrogen were constant with values of $45 \mathrm{~L} / \mathrm{min}$ and $3 \mathrm{~L} / \mathrm{min}$ respectively. Argon was also used as the carrier gas with a flowrate of $3 \mathrm{~L} / \mathrm{min}$ (in order to let fluctuation happen). The powder feeding rate was $10 \mathrm{~g} / \mathrm{min}$. Optic micromorphology of coating structure was captured through an OM (optic microscope). Powder behavior inside the carrier tube was watched and recorded by a video camera through a connected-in transparent PVC tube.

\subsection{Video analyzing}

All videos were analyzed frame-by-frame to detect variation in light intensity and position. As indicated in Fig. 2, a RGB (Red-Green-Blue) image can be converted into a gray value map with several algorithms, such as average method (average over three colors), red channel (only red included), green channel (only green included) and blue channel (only blue included). With the blue channel, it is able to focus on plasma jet while minimizing influence from the particle stream. With both the red channel and green channel, particle stream is enhanced, but a difference exists at the end of plasma jet. With the green channel, the in-flight particle stream can be clearly distinguished from the plasma jet.

Illustration of the selected region is presented in Fig. 3. Length of plasma jet is about $300 \mathrm{~mm}$, and the length of selected particle stream is $233 \mathrm{~mm}$. The selected view B (Fig. 3) covers the whole in-flight particle stream starting from the end of the plasma jet. And view $A$ is selected with a range from $30 \mathrm{~mm}$ above the particle stream's upper edge to $10 \mathrm{~mm}$ below the lower edge. The gray values vary from 0 to 255 means a variation of color from dark to white. The gray degree indicates particle temperature: high temperature results in white color, low temperature conducts a gray color or even darker if the particle cannot be seen. However, a decrease of particle amount also leads to a gray color. Thus, for distinguishing these two differences, the distribution of gray value along view $A$ is dedicated to the variation of particle number and the decrease of gray value along view $B$ is assigned to temperature loss. But with a normal video camera, it is impossible to measure particle temperature precisely. In addition, the variance in injected particle quantity is more interesting in this work. Thus, variation of the gray value mentioned in the current work only denotes the change of particle quality. The significance of which temperature the gray value denoted is not provided.

\subsection{Force equilibrium of particles in the boundary region}

The characteristic of in-flight particles is significantly dominated by powder entering state (from the exit of injector to plasma jet) which is decided by powder behavior during transport inside the carrier tube. Therefore, clarifying powder behavior during transport can help to understand the fluctuation of in-flight particle stream. As the most reasonable method, force analysis can easily predict particle behavior in the carrier tube. The force equilibrium on a single particle can be described with Eq. (1). Considering the immense difference of specific density between carrier gas and feedstock (Table 1 ), the unsteady forces (basset force, the added mass force and the pressure gradient force) are negligible $[15,18]$.

$d \boldsymbol{u}_{p} / d t=\boldsymbol{F}_{\boldsymbol{D}}+\mathbf{g}\left(\rho_{p}-\rho_{g}\right) / \rho_{p}+\boldsymbol{F}_{\boldsymbol{x}}$

\section{[19-21].}

With $\boldsymbol{u}_{\boldsymbol{p}}$, the particle velocity; $\rho_{g}$, the carrier gas density; $\rho_{p}$, the particle density; $\boldsymbol{F}_{\boldsymbol{D}}$, the drag force term; $\boldsymbol{g}$, the gravitational acceleration; and $\boldsymbol{F}_{\boldsymbol{x}}$, other force sources, can be the centrifugal forces in the bent tube in this work.

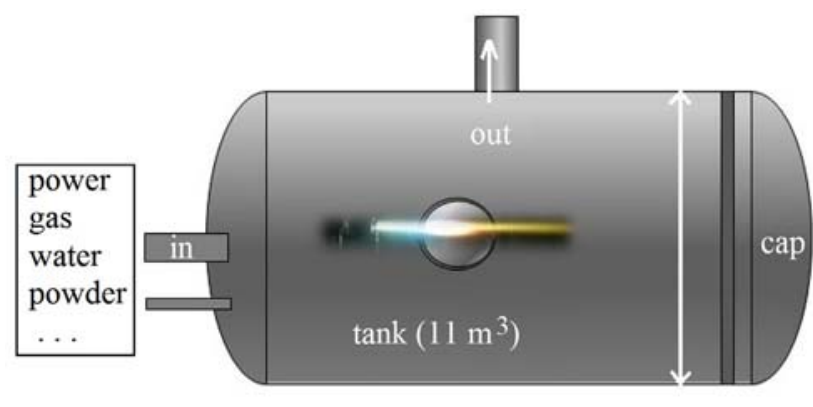

(a)



(b)

Fig. 1. Experimental installation for plasma spraying process: (a) VPS chamber; and (b) cross section of chamber. 


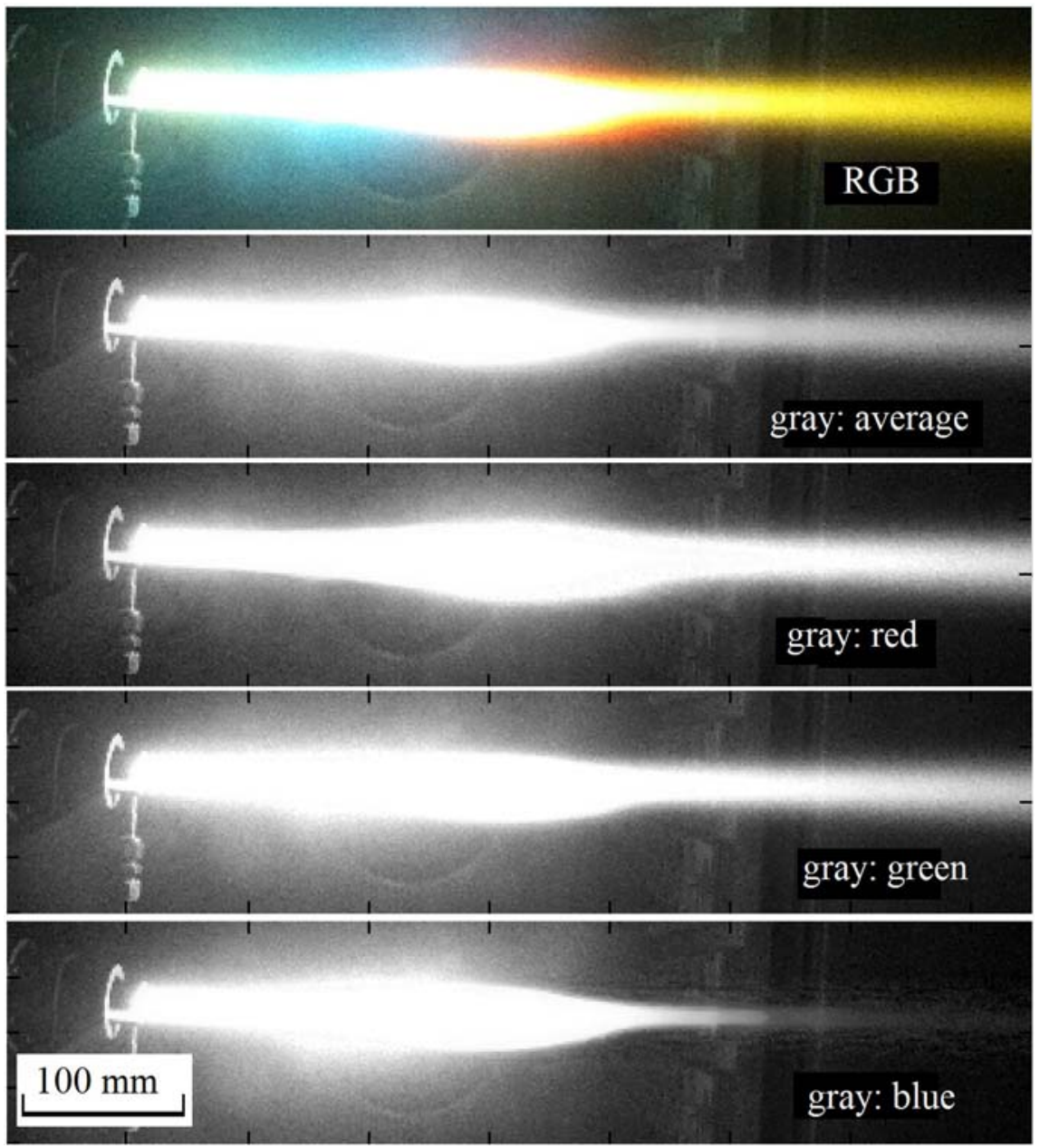

Fig. 2. Illustration of different methods from RGB to gray image. (For interpretation of the references to colors in this figure legend, the reader is referred to the web version of this article.)

$\boldsymbol{F}_{\boldsymbol{D}}$ can be estimated as [20]:

$\boldsymbol{F}_{\boldsymbol{D}}=0.75 \rho_{\mathrm{g}} C_{D}\left(\boldsymbol{u}_{\mathbf{g}}-\boldsymbol{u}_{\boldsymbol{p}}\right)\left|\boldsymbol{u}_{\mathbf{g}}-\boldsymbol{u}_{\boldsymbol{p}}\right| /\left(\rho_{p} d_{p}\right) .\left(\boldsymbol{u}_{\mathrm{g}}\right.$ the carriergas velocity $)$.

$C_{D}$ is determined by $\operatorname{Re}[22,23]$ :

$C_{D}=27.6 / \operatorname{Re}, \operatorname{Re}<1$

$$
\begin{aligned}
& C_{D}=24 / R e+0.15 R e^{0.687}, 1 \leq \operatorname{Re} \leq 1000.0, \\
& C_{D}=0.438, \operatorname{Re}>1000 .
\end{aligned}
$$

Re can be estimated as [16,20]:

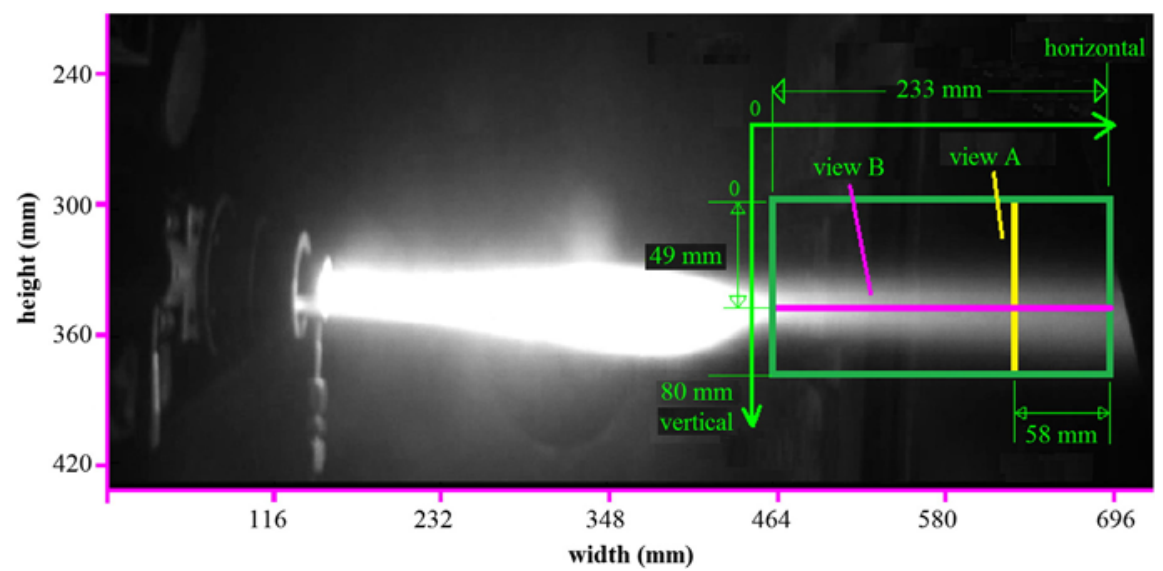

Fig. 3. Illustration of selected region in the green channel. (For interpretation of the references to colors in this figure legend, the reader is referred to the web version of this article.) 
Table 1

Value of variables mentioned in Eq. (1) with a flowrate of $3 \mathrm{~L} / \mathrm{min}$

\begin{tabular}{lllll}
\hline & $\begin{array}{l}\text { Velocity } \\
(\mathrm{m} / \mathrm{s})\end{array}$ & $\begin{array}{l}\text { Viscosity } \\
\left(\boldsymbol{\mu}_{\mathrm{g}}, \mathrm{kg} / \mathrm{m} \cdot \mathrm{s}\right)\end{array}$ & $\begin{array}{l}\text { Diameter } \\
\left(d_{p}, \mu \mathrm{m}\right)\end{array}$ & $\begin{array}{l}\text { Density } \\
\left(\mathrm{kg} / \mathrm{m}^{3}\right)\end{array}$ \\
\hline Argon & 4 & $2.13 \times 10^{-5}$ & - & 1.62 \\
$8 \mathrm{~mol}$ YSZ & $0-4$ & - & $5-200$ & $6.1 \times 10^{3}$ \\
\hline
\end{tabular}

Due to the effect of gravity, particles carried by gas will subside down to the inner wall where the boundary layer exists with velocity distribution indicated by $\boldsymbol{u}_{g}$ in Fig. 4(1). This uneven assignment in carrier gas velocity results in a rolling movement while pushing the particle forward if the particle is spherical or close to spherical (as shown in Fig. 4(2)). As a consequence, the friction resistance from the tube wall is weakened. However, non-spherical particles are more difficult to be carried because of the irregular shape. Moreover, due to the uncertain inner surface condition during powder feeding, it's impossible to accurately gauge friction coefficient. Therefore, according to the work of ElSherbiny et al. [24], an equivalent friction coefficient $\left(C_{f}\right)$ of 0.1 is suggested for ceramic-PVC contact to estimate the wall resistance for further analysis in this work.

In a level straight tube, particles are driven by drag force $\left(\boldsymbol{F}_{\boldsymbol{d}}\right)$ and gravity $\left(\boldsymbol{F}_{\boldsymbol{g}}\right)$ (Fig. 4(3)). But the centrifugal force $\left(\boldsymbol{F}_{\boldsymbol{c}}\right)$ should also be taken into account when the carrier tube is bent, as indicated in Fig. 4(4). In both cases, the resistance force $\left(\boldsymbol{F}_{\mathbf{r}}\right)$ can be estimated with the composite $\left(\boldsymbol{F}_{\boldsymbol{w}}\right)$ of gravity and centrifugal force in the perpendicular direction of tube inner wall, as shown in (3) and (4) of Fig. 4. The drag force is supposed to always follow the tube wall and attrition between in-flight particles is omitted. Thus the resistance force can be calculated as: $\boldsymbol{F}_{\boldsymbol{r}}=C_{f} \boldsymbol{F}_{\boldsymbol{w}}$, and the composite force on the tube wall can be written as: $\boldsymbol{F}_{\boldsymbol{w}}=\boldsymbol{F}_{\mathbf{c}}+\boldsymbol{F}_{\mathbf{g}} \cos \alpha$. The centrifugal force is easily calculated from the velocity and the diameter of pipe bends $\left(d_{b}\right): \boldsymbol{F}_{\boldsymbol{c}}=4 m_{p} \boldsymbol{u}_{\boldsymbol{p}}^{2} / d_{b}\left(m_{p}\right.$, the mass of particle). In the case of level pipe ((3) in Fig. 4), the pipe bend diameter $\left(d_{b}\right)$ is assumed to be infinity to return the centrifugal force a value of zero. The average velocity of particle close to the wall is calculated by carrying integration in the region occupied by a particle (along the perpendicular line of the tube wall) (Fig. 4(1)). Finally, force (F) on a particle is calculated as: $\boldsymbol{F}=\boldsymbol{F}_{\boldsymbol{d}}-\boldsymbol{F}_{\boldsymbol{r}}$. With a positive value, force $\boldsymbol{F}$, is considered as driving force, otherwise it is considered as resisting force. With driving force, the particle is pushed forward while with resisting force the particle can detach from the carrier gas and station to the wall. Thus it gives a big possibility of forming a slug with collision between stationary particles.

\section{Results}

\subsection{Fluctuation in in-flight particle stream}

According to the video captured in this work (as shown in Fig. 2 'RGB'), most particles were found diffusing along the center line of the plasma jet with the chosen carrier gas flowrate of $3 \mathrm{~L} / \mathrm{min}$. While any change in operating parameters, such as the current, the plasma gas,



Fig. 4. Velocity and force of a single particle close to the inner wall of the carrier tube. 
the voltage, and the entering state of particles, can result in variation in particle trajectories. However, the operating parameters were maintained in constant, the arc root was unavoidably unstable which induced fluctuation in particle trajectories. With the video camera, variation in in-flight particle stream was observed and stream width and vertical position were found unstable as well as the gray value distribution along view $A$ and view $B$. The stream width and vertical position were defined by comparing the gray value with a predefined threshold that the particle trajectory can be well distinguished from the background. In Fig. 5, the gray map presents in-flight particle stream along view $A$ with a duration of $40 \mathrm{~s}$. The region between upper edge (yellow curve) and lower edge (red curve) is specified with a threshold of 60 that means only pixels with gray values bigger than 60 are included in this region. And by averaging the vertical position of the upper edge and lower edge, the middle position of stream is defined and drew in green curve (mid). With these three curves, the fluctuation of particle stream is clearly characterized. The video focus turned from plasma jet to in-flight particle stream at 4 th second. The increase of stream vertical position, indicated by the arrows ('auto-focus'), is caused by the auto-focus action of the video camera. From the 5th second to the 40th second, the stream sways as a mixture of high frequency instability ( $>5 \mathrm{~Hz}$, sharp dentate in three curves) and low frequency waves ( $<1 \mathrm{~Hz}$, smooth wave indicated by white waves). However, the low frequency waves are not clear in the upper edge which means that the upstream was not sensitive to such fluctuation.

The width of in-flight particle stream was obtained by measuring the width between the upper edge and lower edge in Fig. 5. As the 'original' curve displayed in Fig. 6, the stream width was found erratic during the watching time. The width of in-flight particle stream varies between the maximal value $42 \mathrm{~mm}$ and the minimal value $30 \mathrm{~mm}$ as a combination of high frequency fluctuation and low frequency fluctuation. Meanwhile, three waves are clearly observed in the 'original' curve of Fig. 6. And it's easier to obtain these waves with a filter operation to shield out all high frequency parts $(>5 \mathrm{~Hz}$ ) ('HF' in Fig. 6), the rest part is outlined as a smooth curve in Fig. 6 indicated with 'LF'. The time scale of these three waves varies from $5 \mathrm{~s}$ almost to $20 \mathrm{~s}$ that agrees with the result in Fig. 5. With Fig. 6, it is clear that the filtered width has a value between 37 and 38 ('LF') which is close to the average width calculated from the blue line, 37.5. The filtered high frequency part is also provided in Fig. 6 varying between -4 and 4 (as 'HF') with mean value very close to zero $\left(10^{-26}\right)$ which indicates a white noise signal that has no significant influence on the final performance. Because the maximal

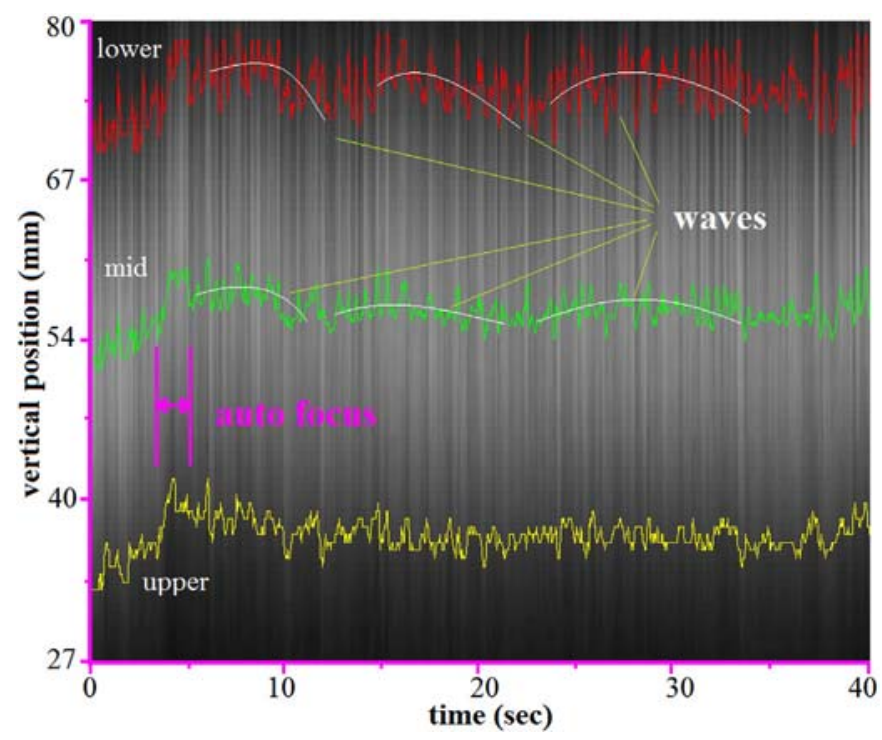

Fig. 5. Stream width and vertical position detection (in view A). (For interpretation of the references to colors in this figure, the reader is referred to the web version of this article.) frame rate is $30 \mathrm{fps}$, all information with higher frequency, for example the arc fluctuation [25], is not able to be identified.

In Fig. 7(a), the distribution of gray value along view A was depicted in 3D space. The surface color aligns with the gray value on the vertical axis ('gray value' in Fig. 7(a)). The peak position of the surface in Fig. 7(a) is the same as the mid position in Fig. 5. Because view A is far away from the plasma jet, the maximal value of stream intensity is below 160 . That means the particle temperature here is lower than temperature at the plasma jet end. This surface shows a Gaussian profile which indicates congregation of particles in the core region of particle stream. As above mentioned, the decrease of gray value from the center line to the upper edge and to the lower edge implies a reduction of particle quantity. Along the time axis, obvious fluctuations are found in the core region. As displayed in Fig. 7(b), most of the peaks wave around 130 while some peaks are over 150 and some others are lower than 120. Once again, the three wave-like fluctuations, as mentioned in Figs. 5 and 6, are observed in Fig. 7(b).

Similar fluctuations were also found in view B exposing time dependency. In Fig. 8, the change of gray value from left to right mainly implies the decrease of particle temperature. The variation of gray value along the time axis indicates variation in particle stream density: high density means more particles, low density means less particles. The sharp needle on the time axis presents the high frequency fluctuation in particle stream density. Low frequency variation also exists as illustrated in Fig. 8 with three solid curves in time scale from around $5 \mathrm{~s}$ to about $20 \mathrm{~s}$.

As illustrated in Fig. 3, an increase in vertical position of in-flight particle stream demonstrates a lower position of the lower edge. Increases in stream width and density indicate that more particles have been injected into the plasma jet. The reason for the fluctuation in particle stream width and density may mainly originate from the instability of powder feeding which can cause unstable entering state of particle.

For understanding the mechanism of such fluctuation, the entering state of injected particles should be elucidated. The momentum of inflight particles comes from the carrier gas (radial velocity) and plasma jet (axial velocity). Assuming that in a small enough instant the whole momentum of the carrier gas is constant $\left(\Delta E_{g}\right)$, and then this momentum completely transfers to the particle momentum $\left(E_{p}\right)$ to give particles an entering velocity (Eq. (2)). Then in the next instant, a sudden increase in the amount of injected particles happens ( $m>n$ in Eq. (2)) as 'powder flooding'. Therefore, the new momentum of particles released from the injector is lower $\left(E_{p}{ }^{\prime}<E_{p}\right)$ [26]. According to the results reported in literature [27], the radial displacement (vertical) of the injected powder in the plasma jet is determined by the injection velocity (entering velocity). Thus the more particles injected, the lower entering velocity and the shorter radial displacement will be obtained.

$\Delta E_{g}=\sum_{1}^{n} E_{p}=\sum_{1}^{m} E_{p}^{\prime}$

where $\Delta E_{g}$ denotes the total momentum of the carrier gas within a small enough instant; $E_{p}$ and $E_{p}{ }^{\prime}$ denote the particle momentum; and $n$ and $m$ indicate the total number of injected particle in different instants.

Meanwhile, with the consideration of size distribution of feedstock, the axial velocity of injected particles may be different. Big particles have been reported to have lower axial velocity in plasma jet compared with smaller size particles [22]. That means coarse particles have more flight time in the plasma jet as well as more chance to cross the plasma jet cone region than the small particles. Therefore, their trajectories become higher in the radial direction as shown in Fig. 9(a) in which the relation of trajectories between particles with different sizes was shown $\left(d_{3}>d_{2}>d_{1}\right)$. Moreover, when more particles were released to the plasma jet ('powder flooding'), the average entering velocity of particles is surely lower. As a consequence, the trajectory will be shallower in the radial direction (Fig. 9(b)) and have less chance to cross the plasma jet core region. In this case, before heating up to a high enough temperature to achieve molten state, most particles are accelerated out of the hot region. Therefore, it can forecast that when 'powder flooding' 


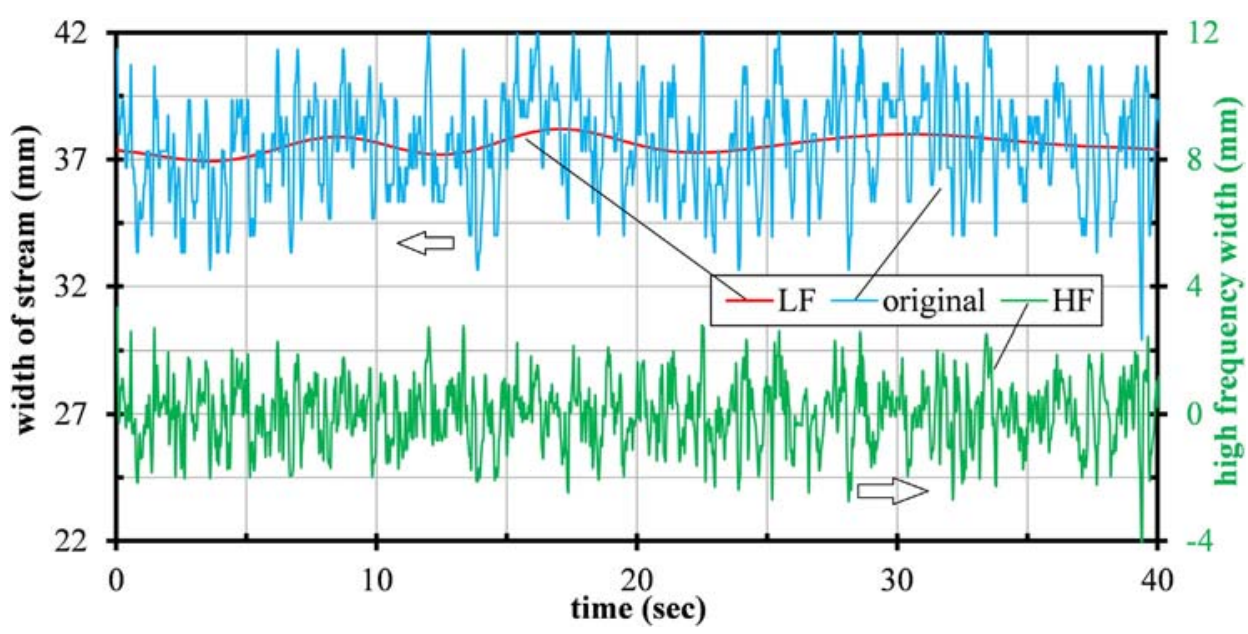

Fig. 6. Variation of in-flight particle stream width and filtered width with low frequency (LF) and high frequency (HF) obtained in view A.

\section{a}



b

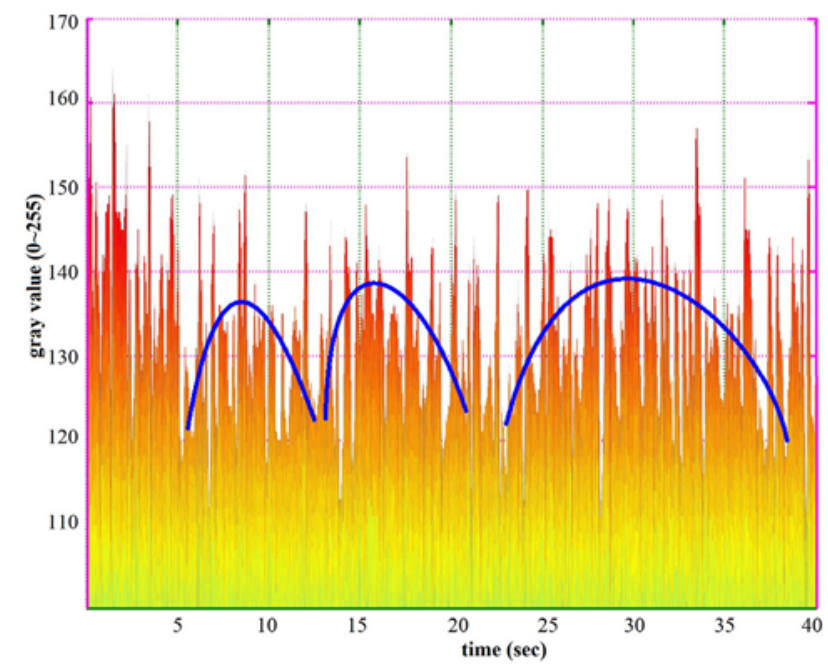

Fig. 7. Fluctuation of in-flight particle streams along view A: (a) 3D view and (b) zoom of cone region. happens, more pores will be present in the coating and the coating can be very inhomogeneous.

\subsection{Instability in powder feeding}

In the thermal spray process, feedstock can be precisely fed either by a suction feeder (negative pressure sucking) or a vibration feeder and then carried by a neutral gas (normally, argon) to the injector. Considering the distance between the powder feeder and the injector (around $3 \mathrm{~m}$ ), a 5-m-long PVC (Polyvinyl Chloride) tube with an inner diameter of $4 \mathrm{~mm}$ is used to conduct powder. Although, the feeding precision of the powder feeder is high enough, particles injected to the plasma jet are often found with different entering states (velocity, position and angle) which further cause different trajectories crossing the plasma jet. Powder behavior inside feeding tube obviously plays governing part on the entering state of particles and only with which the "powder flooding' phenomenon can be explained.

As presented in Fig. 6, fluctuation in in-flight particle stream is composed of high frequency part and low frequency part. By exposing the connected transparent carrier tube in a bright light beam which was reduced to avoid dazzling the camera, clear videos were captured with $30 \mathrm{fps}$ to detect fluctuations with different frequencies. In Figs. 10 and



Fig. 8. Fluctuation of in-flight particle stream along view $B$. 


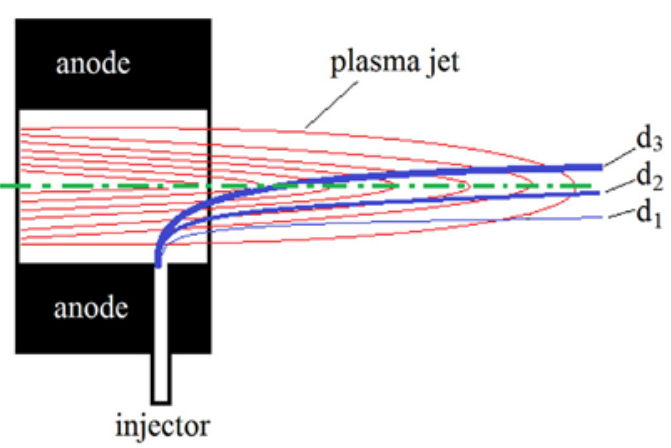

(a) normal feeding

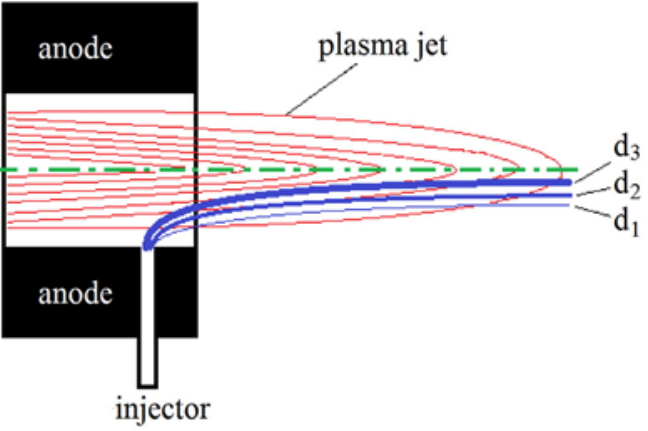

(b) powder flooding

Fig. 9. Different trajectories of in-flight particle in normal feed and dense feed.

12 frames of images were aligned with time from $0 \mathrm{~s}$ to $11 / 30 \mathrm{~s}$. At the beginning ((1) in Fig. 10), the tube is clear between two dark edges (outer diameter is $6 \mathrm{~mm}$, inner diameter is $4 \mathrm{~mm}$ ). The arrow in the first frame marks the feeding direction, and the ellipses in the rest of the frames indicate the interesting area. From the second frame $(1 / 30 \mathrm{~s})$ to the fourth frame $(3 / 30 \mathrm{~s})$, a detectable increase in darkness is observed close to the lower edge which means an increase of powder feeding rate as well as the amount of particles settling to the inner wall. Because of the colossal divergence in density between argon and YSZ particles, most powder sunk toward the lower edge when fed through a horizontal or slope tube. Although, the area size of the dark shadow doesn't make sense of the exact feeding rate, it clearly shows the instability of powder behavior inside the carrier tube.

When comparing the shadow size of frame 5 with that in frame 9 , the feeding, in some degree, is stable. But then the difference found between frame 9 and frame 10 connotes a sudden decrease in powder feeding rate that implies that the feeding rate may drop from a high level to a lower level only in $1 / 30 \mathrm{~s}$, for example, from $30 \mathrm{~g} / \mathrm{min}$ to $10 \mathrm{~g} / \mathrm{min}$. Thus, it is clear that the area size of the shadow has a variation procedure as: increase-stable-decrease with a time scale of about
$1 / 3$ s. Such variation observed from frame 2 to frame 10 can be always observed during the whole feeding process with different frequencies and different intensities. As illustrated in Fig. 9, such instability in powder feeding will directly cause a fluctuation in particle trajectories, and also can lead to fluctuation in impacting state of in-flight particles which prevents particles from completely melting, and come into pores in the coating later.

In order to detect the low frequency variation of the powder feeding state, 100 pixels, marked in the top-left corner of Fig. 11, were selected crossing the carrier tube. The gray value of pixels between 25 and 55 was displayed as a gray map with time axis (Fig. 11). The gray value shifts between 60 and 180 which means dark and bright respectively. According to this figure, in the first $2 \mathrm{~s}$, the carrier tube is clear and most of the pixels in the selected area (25-55 pixels) have gray values bigger than 120 . Then several pulse-like peaks are found between the 3rd second and the 8th second. It means that powders start to unstably settle and intermittently accumulate on the carrier tube wall. Then more powders cross the selected line to cause a decrease of gray value from 120 to value below 80 between pixel 25 and pixel 35. As depicted with white solid curves in Fig. 11, waves with low frequency can be
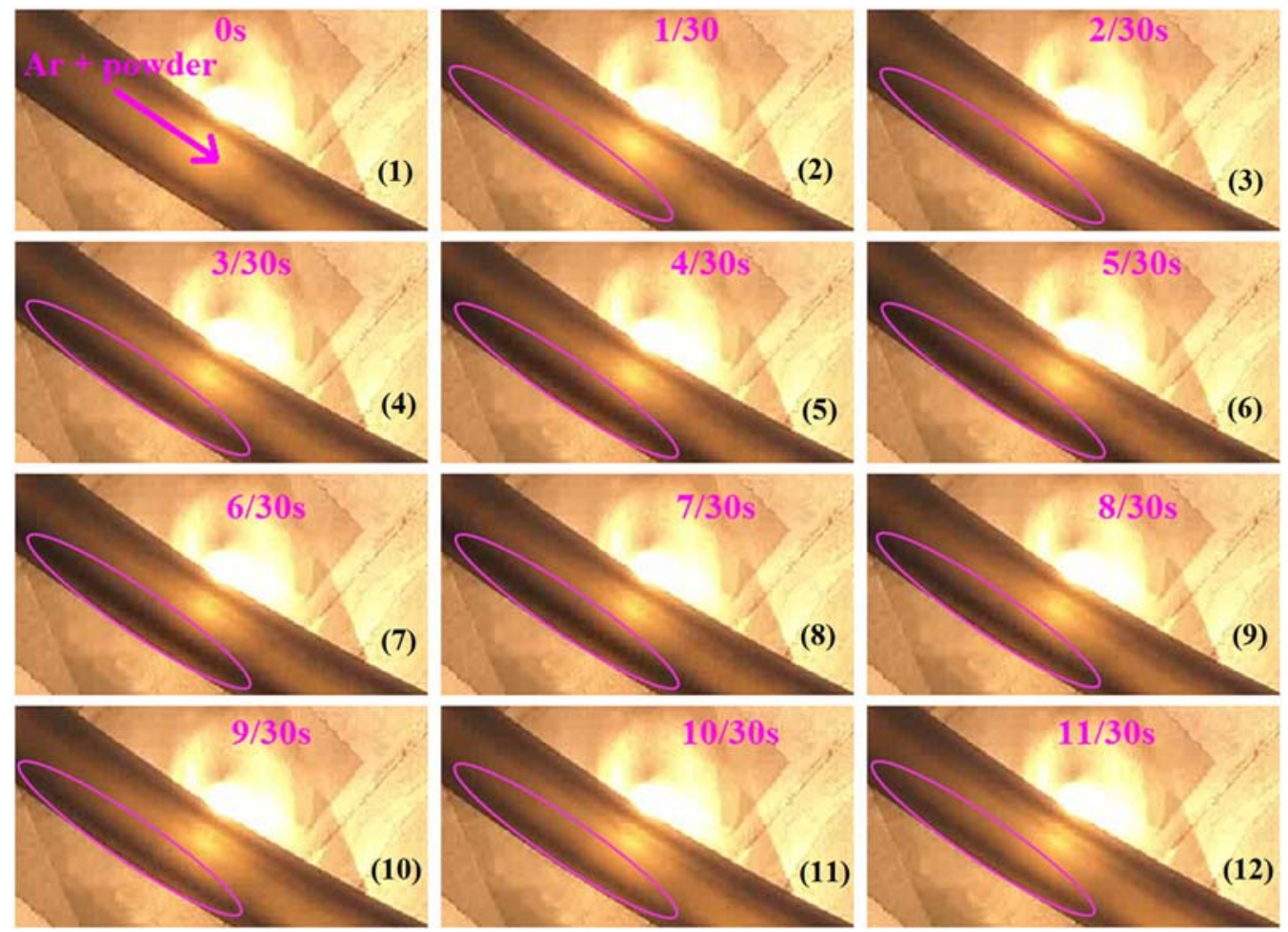

Fig. 10. High frequency fluctuation detected in the carrier tube (downslope). 


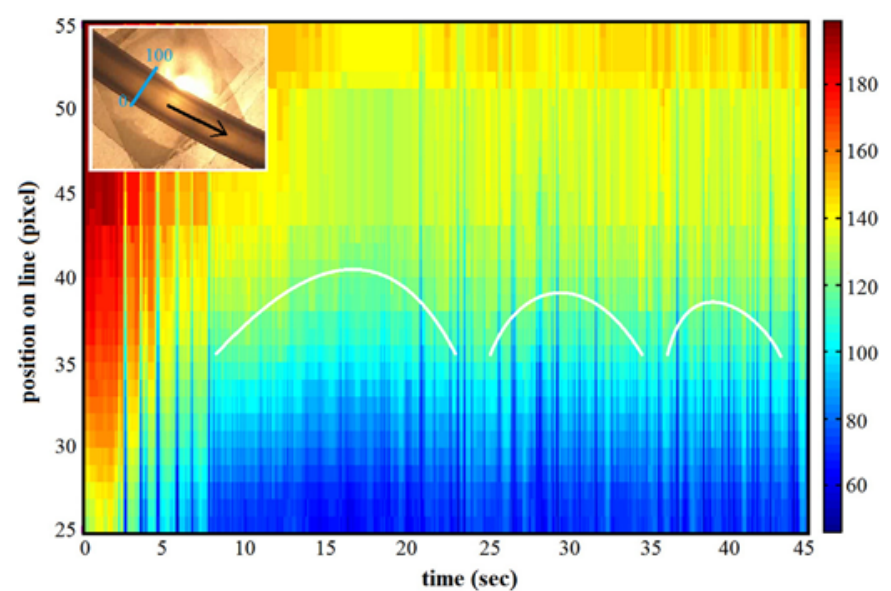

Fig. 11. Fluctuation of powder feeding crossing the selected line.

found at several regions: $8 \mathrm{~s}-25 \mathrm{~s}, 25 \mathrm{~s}-35 \mathrm{~s}$ and $35 \mathrm{~s}-45 \mathrm{~s}$. These waves with various time scales are shaped by numerous pulse-like fluctuations. Within these waves, several pulses can be found deeply penetrated into the upper region that implies big accumulation of powder on the downhill slope with very short existence $(<1 \mathrm{~s})$.

The powder behavior on uphill slope was also watched by bending the carrier tube with radius about $150 \mathrm{~mm}$ (Fig. 12). The arrows indicate feeding direction, from right to left as shown in Fig. 12. Comparing areas located by ellipses in Fig. 12, the accumulation of powder can be found around the lower edge of the bent tube. It should be noticed that during the first $14 \mathrm{~s}$, the increase of powder accumulation is slight. The accumulation of particles can be considered as the growth of slug due to the collision between settled particles. Once the slug born, the carrier gas has no chance to completely carry these particles again. As indicated in Fig. 12, the dark shadow can be always watched from the 14th second till the end of the video. However, carrier gas can corrode and renew and push the slug that may bring birth of another new slug and can transfer particles between them, as displayed in Fig. 12 between $42 \mathrm{~s}$ and $51 \mathrm{~s}$. After $42 \mathrm{~s}$, too much powder has been restrained in the dark shadow area which almost spreads to the uphill region. However, the carrier gas never stops the erosion on restrained powder. Part of restrained powder starts to be swirled up at the 39th second following the carrier gas: some of the rolled-up powder is successfully carried up again by the carrier gas that means that the amount of particles injected into the plasma jet can suddenly increase and then quickly subside; and the rest of the particles are transferred to the next slug as the ellipse shows at the 51st second. As a consequence, obvious fluctuation exists in in-flight particle stream and happens from time to time.

\subsection{Fluctuation in coating structure}

In a thermal spraying experience, unavoidable bends/elbows, as shown in Fig. 12, may exist and cause accumulation of the carried powder and thus result in instable entering state of powder. A coating was prepared to identify the influence of feeding fluctuation on coating structure by centrally stationing the torch in front of the substrate for $5 \mathrm{~s}$ within which a fluctuation in powder feeding happens.

As displayed in Fig. 13, the coating has a maximal thickness of $1.2 \mathrm{~mm}$ and presents a clear three-layer structure (upper layer, mid layer and lower layer). The upper layer and the lower layer are obviously denser and more homogenous than the mid layer which is filled by different size pores. At the outer ring area (edge), the mid layer becomes denser and the amount of big pores evidently decreases.

For easy understanding, the radial direction of substrate is titled as $\mathrm{X}$ (abscissa) and the depositing direction is defined as $\mathrm{Y}$ (ordinate). This cross section of coating structure was assembled by six original images of optical micromorphology. Actually, a gray image as Fig. 13 can be considered as a matrix with structure of $m$ rows (axis $Y$ ) $\times n$ columns (axis X). By fixing one dimension (row or colon), a local mean value of porosity ratio can be calculated along the other dimension (colon or row). Local mean porosity ratio thus was estimated along axis Y (fix

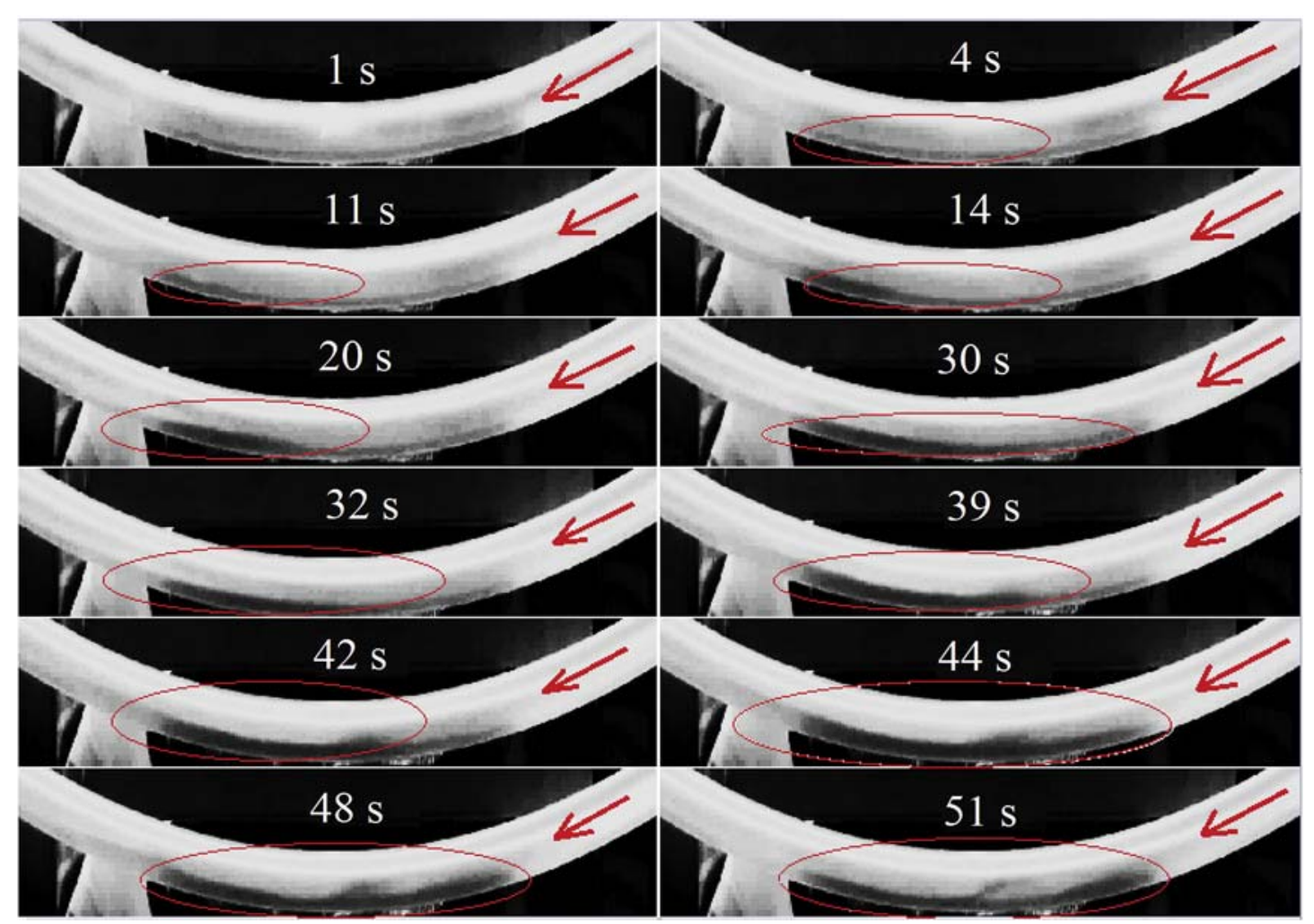

Fig. 12. Fluctuation and accumulation of powder in the tube with long period (upslope). 


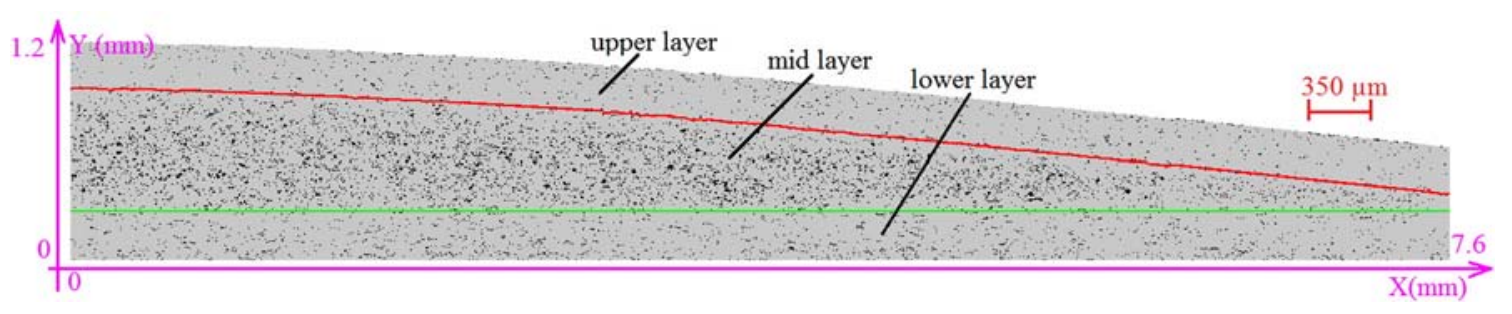

Fig. 13. Cross section of coating established by APS.

axis $\mathrm{X}$ and average along axis $\mathrm{Y}$ ) and axis $\mathrm{X}$ (fix axis $\mathrm{Y}$ and average along axis $\mathrm{X}$ ) as shown in Figs. 14 and 15 respectively.

According to Fig. 14, the mean value of porosity ratio for the whole cross section is $5.05 \%$ as indicated in the lower layer in Fig. 14. And the partial average porosity ratio in three layers is: $2.2 \%$ in upper layer, $7.8 \%$ in mid layer and 3.3\% in the lower layer. In the mid layer, the average value is $8.8 \%$ for the first $6 \mathrm{~mm}$ (from $0 \mathrm{~mm}$ to $6 \mathrm{~mm}$ of axis $\mathrm{X}$ ), and for the last $1.6 \mathrm{~mm}$ (from $6 \mathrm{~mm}$ to $7.6 \mathrm{~mm}$ of axis $\mathrm{X}$ ) the average porosity ratio is only $4.0 \%$. Moreover, as an evidence of big pores, the maximal local porosity ratio in the upper layer is about $11 \%$ at $4.2 \mathrm{~mm}$ of axis X; in the mid layer, the maximal value is about $20 \%$ at several positions ( $4.4 \mathrm{~mm}, 5.95 \mathrm{~mm}$ and $7.5 \mathrm{~mm}$ of axis X); and in the lower layer, the maximal value is about $15 \%$ at $4.6 \mathrm{~mm}$ of axis X. Therefore, it is clear that the fluctuation in powder feeding has a significant effect on coating structure (the existence of three layers) but has less effect on the outer ring area ( $6 \mathrm{~mm}-7.6 \mathrm{~mm}$ of the mid layer).

In Fig. 15, the porosity ratio calculated by fixing axis $Y$ and averaging along axis $\mathrm{X}$ is displayed with less deviation compared with Fig. 14. Because of the uneven thickness of coating, the interface between the upper layer and mid layer is bent. Consequently, when estimating the mean value along axis $\mathrm{X}$, a cross region exists between the upper layer and mid layer as indicated in Fig. 15. The dot-dash line in Fig. 15 denotes the average porosity ratio for the whole area, $5.05 \%$, as mentioned in Fig. 14. In this case, the variance in porosity ratio can be understood layer-by-layer since axis $\mathrm{Y}$ is aligned with depositing direction. In the lower layer, after the first layer of coating impacting upon the cold surface of the substrate, the temperature of the substrate starts to increase as a consequence of heat conduction that will attain better impacting condition for the following layers. After some instant, a momentary increase of powder feeding rate happens and accordingly causes improper impacting state of particles that will accrue more pores in lamellas. With subsidence of this momentary variance, quantity of injected particles decreases and the radial displacement becomes deeper which allows particles to regain higher temperature when impact happens. Meanwhile, considering the enhanced surface temperature of substrate from plasma jet and deposited particles, the lamellas in the upper layer region finally have fewer pores trapped in. When coating is established by scanning the substrate with the plasma jet, void defect as found in the mid layer may be distributed over the entire substrate surface to form global fluctuation in some lamella. In parallel, such defects may also be consistently allocated between different lamellas at the same place which results in local fluctuation. Coatings with such disordered inhomogeneous structure often exhibit poor reproducibility in performance. For precisely controlling the coating property, the mechanism of fluctuation in powder feeding should be clarified.

\subsection{Particle behavior in the carrier tube}

\subsubsection{The Stokes number}

Particle behaviors inside the carrier tube are governed by pneumatic conveyance. For describing the interaction between particles and carrier gas, the Stokes number (St) is obtained by calculating the ratio of the particle aerodynamic response over the characteristic time of the carrier gas motion $[13,28]$.

$S t=\rho_{p} d_{p}^{2} u_{g} /\left(18 \mu_{g} L\right) \times 10^{-12}$

with $\rho_{p}$, feedstock density, $\mathrm{kg} / \mathrm{m}^{3} ; d_{p}$, particle diameter, $\mu \mathrm{m} ; \boldsymbol{u}_{\mathrm{g}}$, carrier gas average velocity, $\mathrm{m} / \mathrm{s} ; \mu_{\mathrm{g}}$, the dynamic viscosity of carrier gas, $\mathrm{kg} / \mathrm{m} \cdot \mathrm{s}$; and $L$, the length of the carrier tube, $\mathrm{m}$.

For the flow system mentioned in this work (carrier gas + powder), particles with small Stokes numbers $(\ll 1)$ respond rapidly to the change in carrier gas motion and the difference of velocity between

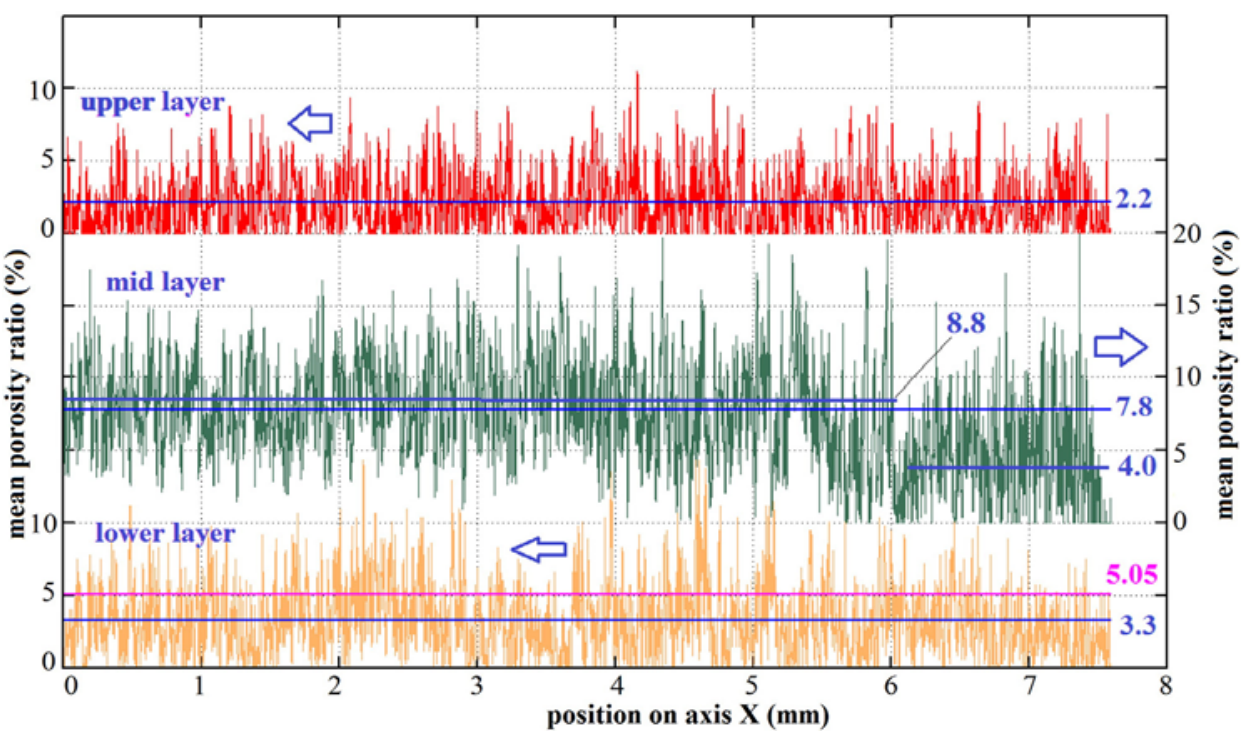

Fig. 14. Porosity ratio calculated as the average value along axis Y. 


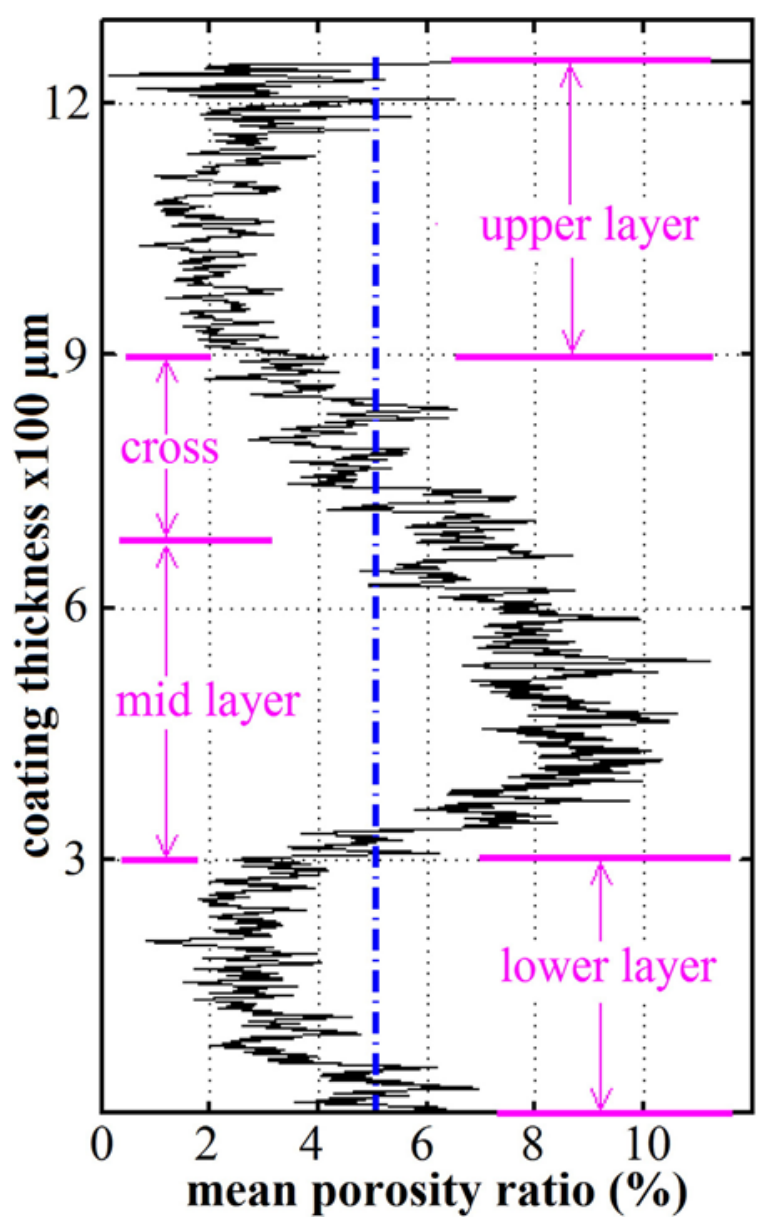

Fig. 15. Porosity ratio calculated as the average value along axis $\mathrm{X}$.

the gas phase and solid phase is quite small. Particles with large Stokes numbers ( $\gg 1$ ) will not be able to follow the change in gas motion [13]. Considering the effect of carrier gas flowrate and the influence of the carrier tube length, the Stokes number of particles inside a level straight tube can be calculated with consideration of size effect. Fig. 16 provides the Stokes number with different flowrates of the carrier gas at an exit standing $1 \mathrm{~m}$ away from the powder feeder outlet. By increasing the flowrate, the Stokes curves climb up and gas motion is enhanced which makes it more difficult for the particles to follow. Meanwhile, the cross point between the Stokes curves and the dot-dash line moves toward 0 which means more particles turn to upper region $(>1)$. For example, with a flowrate of $3 \mathrm{~L} / \mathrm{min}$ particles with a diameter smaller than $125 \mu \mathrm{m}$ always have a Stokes number below 1 , while with a

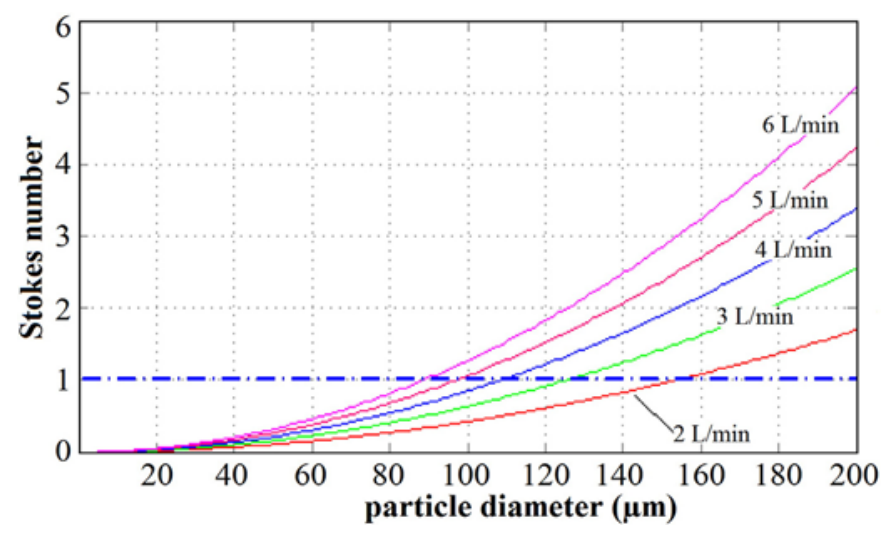

Fig. 16. The Stokes number under different flowrates of carrier gas ( $1 \mathrm{~m})$. flowrate of $6 \mathrm{~L} / \mathrm{min}$ particles with a diameter smaller than $90 \mu \mathrm{m}$ have a Stokes number below 1 and particles with diameter between $90 \mu \mathrm{m}$ to $125 \mu \mathrm{m}$ have a Stokes number bigger than 1 . This also means that the particle needs more time to achieve a stable velocity.

Fixing the carrier gas flowrate at $3 \mathrm{~L} / \mathrm{min}$, the Stokes number along the tube is estimated to decrease with length, as shown in Fig. 17. Thus, through a carrier tube with the proper length, the powder injected into the plasma jet will be able to achieve a relatively constant state. In addition, small size particles exhibit high capacity in following the change of gas motion in each case, no matter under which flowrate of carrier gas and no matter at which distance to the powder feeder. Therefore, the fine particles are earlier to reach a stable velocity.

\subsubsection{Transport of particles in the boundary region}

The time for achieving velocity equilibrium between particle and carrier gas in boundary region can be estimated supposing that a level straight pipe is used. The initial velocity of particles is set the same as that of the carrier gas. As shown in Fig. 18, the velocity of coarse particles becomes stable after $1 \mathrm{~s}$ which means before attaining a stable velocity a stabilizing distance of about $1.4 \mathrm{~m}$ is necessary. For particles with small sizes, the change in velocity is slight enough to be considered as stable even at the very beginning. Therefore, with results in Figs. 16-18, it is clear that fine particles are easier to reach a stable state even in the boundary region and more sensitive to the change of carrier gas motion. It's easy to infer that in a level straight tube, the driving force decreases toward zero but never reaches a negative value which means particles have less chance to stop and to stack up as a slug.

When considering the bending effect of carrier tube, an imaginary ring of the carrier tube with a bend diameter $\left(d_{b}\right)$ of $0.3 \mathrm{~m}$ is proposed and displayed in Fig. 19. With this proposal the carrier gas and powder (Ar + YSZ) flow in a perfect ring of bent tube following the arrow. The cross-section diameter $\left(d_{c}\right)$ of the tube is $4 \mathrm{~mm}$ which is an effective area for powder transport. The relations between these three forces (gravity $\boldsymbol{F}_{\boldsymbol{g}}$, drag force $\boldsymbol{F}_{\boldsymbol{d}}$ and centrifugal force $\boldsymbol{F}_{\boldsymbol{c}}$ ) are denoted with angle alpha $(\alpha)$ which varies from $0^{\circ}$ to $359^{\circ}$. Therefore, driving force $(\boldsymbol{F})$ can be noted as the tangential force supposed to always follow the carrier tube inner wall. Therefore, by varying the value of alpha and the diameter of particle in the force calculation mentioned above, the change of driving force on particles can be estimated.

Driving forces on particles with different diameters along the imaginary ring of the carrier tube are presented in Fig. 20 from (a) to (e) in the form of four circles which indicate (1) $\boldsymbol{u}_{p}=0.97 \boldsymbol{u}_{g}$, (2) $\boldsymbol{u}_{p}=$ $0.7 \boldsymbol{u}_{\boldsymbol{g}}$, (3) $\boldsymbol{u}_{\boldsymbol{p}}=0.3 \boldsymbol{u}_{\boldsymbol{g}}$ and (4) $\boldsymbol{u}_{\boldsymbol{p}}=0.0 \boldsymbol{u}_{\mathrm{g}}$ with $\boldsymbol{u}_{\boldsymbol{g}}$ the integrated mean velocity of the carrier gas in the boundary region. Lines distributed along circles present force with scale at the lower-left corner in each subgraph. The length of these lines signifies the magnitude of tangential force on particles. In addition, lines outside the circle, e.g. all lines sent



Fig. 17. The Stokes number at different places along the tube $(3 \mathrm{~L} / \mathrm{min})$. 




Fig. 18. Time for velocity equilibrium with different particle sizes.

out from circle (4) in (a), (b), (c), (d) and (e) of Fig. 20, present a positive tangential force (driving force). While lines inside the circle or have a length near zero imply non-positive local force (resisting force), e.g. lines of circle ( 1 ) between $0^{\circ}$ and $180^{\circ}$ in (a), (b), (c), (d) and (e) of Fig. 20.

All particles are assumed close to the carrier tube inner wall which means that particles with different sizes will obtain different velocities. That's why the scales are enlarged with the increase of diameter from subgraphs (a) to (f) in Fig. 20. For particles with a diameter of $10 \mu \mathrm{m}$, the driving force (or tangential force) is always positive when transported with velocity $\left(\boldsymbol{u}_{\boldsymbol{p}}\right)$ not bigger than $0.7 \boldsymbol{u}_{\boldsymbol{g}}$ (circles (2), (3) and (4) in (a) of Fig. 20). When increasing transport velocity ( $\left.\boldsymbol{u}_{\boldsymbol{p}}\right)$ to $0.97 \boldsymbol{u}_{g}$, the driving force on particles turns into resisting force in the region between $0^{\circ}$ and $180^{\circ}$ which will cause a decrease in velocity. Obviously, particles will reach equilibrium in velocity and force with an equilibrium velocity between $0.7 \boldsymbol{u}_{\mathrm{g}}$ and $0.97 \boldsymbol{u}_{\mathrm{g}}$. Moreover, with the increase of particle diameter, the equilibrium velocity decreases to

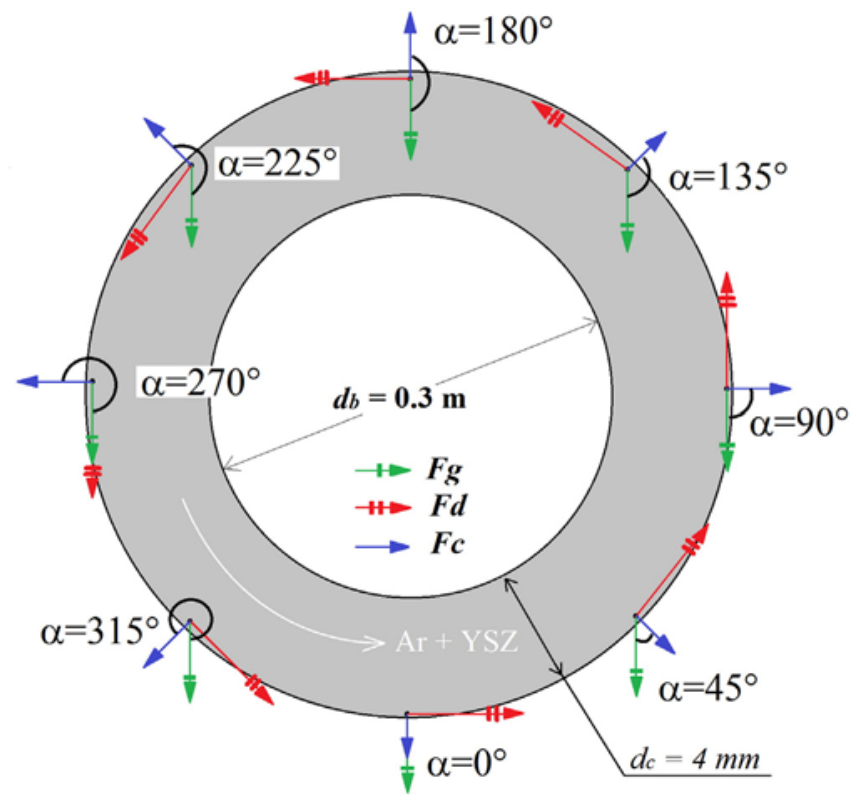

Fig. 19. Force distribution of particles on the inner wall of the assumed ring of tube.
$0.7 \boldsymbol{u}_{g}$ for particles with a diameter of $20 \mu \mathrm{m}$ in subgraph (b), to $0.3 \boldsymbol{u}_{g}$ for particles with a diameter of $50 \mu \mathrm{m}$ in subgraph (d) and to $0.0 \boldsymbol{u}_{\mathrm{g}}$ for particles with a diameter of $100 \mu \mathrm{m}$ in subgraph (e).

The existence of a transition region can be noticed for all particles in the region between $0^{\circ}$ and $180^{\circ}$. The tangential force will turn from driving force to resisting force when entering the transition region from $0^{\circ}$ and the resisting force turns into driving force when leaving the transition region at $180^{\circ}$ for most particles. In Fig. 20 , transition regions are presented with two bold dashed curves (green) in each subgraph. These bold dashed curves start from circle (1) at $0^{\circ}$ and $180^{\circ}$, and traverse other circles as a result of decreasing transport velocity. But the termination of these curves depends on the size of particles, for example in subgraph (a) the two dashed curves terminate between circle (1) and circle (2), but in subgraph (b) the termination is located between circle (2) and circle (3). Moreover, these two heavy dashed curves can be close to each other before reaching circle (4) for particles with sizes of $50 \mu \mathrm{m}, 30 \mu \mathrm{m}, 20 \mu \mathrm{m}$ and $10 \mu \mathrm{m}$. That means all tangential forces are positive on circle (4) for these particles. Meanwhile, for particles with large sizes $(>100 \mu \mathrm{m})$, these two dashed curves cannot meet each other without crossing circle (4), as shown in (e) and (f). Especially, in subgraph (f), these bold dashed lines present edge changes of transition region with increasing particle diameters from $100 \mu \mathrm{m}$ to $200 \mu \mathrm{m}$ while keeping the transport velocity $\left(\boldsymbol{u}_{\boldsymbol{p}}\right)$ zero $\left(0 \boldsymbol{u}_{\boldsymbol{g}}\right)$.

In subgraph (f), a decrease in the lower edge of the transition region is found from about $50^{\circ}$ to $28^{\circ}$ by increasing the particle size from $100 \mu \mathrm{m}$ to $200 \mu \mathrm{m}$. While the upper edge of transition region increases from $116^{\circ}$ to $136^{\circ}$ which means that the transition region becomes wider for particles with larger sizes which implies that the chance to station down is bigger. For coarse particles $(>200 \mu \mathrm{m})$, the tangential forces between $28^{\circ}$ and $136^{\circ}$ are predictably non-positive which means that these coarse particles cannot be well transported under the current carrier condition ( $3 \mathrm{~L} / \mathrm{min}$ of argon and $d_{c}=4 \mathrm{~mm}$ ). Due to the collision effect between particles, slug/slurry with bigger sizes may exist. Therefore, accumulation of particles often happens in this region (from $28^{\circ}$ to $136^{\circ}$ ). And learning from the extending tendency of the two dashed lines in subgraph (f), it is sure that the transition region will gradually broaden toward $0^{\circ}$ at the lower edge and toward $180^{\circ}$ at the upper edge with increasing particle size. Therefore, slug as mentioned in Fig. 12 can be observed.

Additionally, it should be noted that for all particles the tangential force located at $90^{\circ}$ always has a minimal value that can be considered as a decision for determining the carrier state of particles. As shown in (f) of Fig. 20, for particles with diameter bigger than $100 \mu \mathrm{m}$, even in a stationary state $\left(\boldsymbol{u}_{\boldsymbol{p}}=0 \boldsymbol{u}_{g}\right)$, the drag force is not enough to conquer resistance from gravity in the region between $28^{\circ}$ and $136^{\circ}$ in the boundary layer. As a solution, the carrier gas flowrate should increase to the proper level. Without any change in other parameters, the change of tangential force at $90^{\circ}$ is calculated by increasing the carrier gas flowrate from $2 \mathrm{~L} / \mathrm{min}$ to $6 \mathrm{~L} / \mathrm{min}$. Fig. 21 displays the effect of variation in carrier gas flowrate on the tangential force of particles. The bold dot-dash line located at ' 0 ' of the ordinate depicts the threshold for particle transport: below this line means negative driving force (or resisting force) that particles are unable to be well transported, while above this line means particle can be well transported. The cross point between data curves and the threshold line indicates a transition in particle transport state: particles with diameter smaller than the crossing value are able to be well transported; but particles with sizes bigger than this crossing value will have a big chance to stack up and to form a slug, for example, particles smaller than $35 \mu \mathrm{m}$ can be well transported in the transition region with carrier gas flowrate of $2 \mathrm{~L} / \mathrm{min}$. More particles $(<75 \mu \mathrm{m})$ can be transported when increasing the flowrate to $3 \mathrm{~L} / \mathrm{min}$. It is obvious that the powder feeding is enhanced by the increasing carrier gas flowrate. A flowrate of $4.5 \mathrm{~L} / \mathrm{min}$ can provide enough power to transport powder with a granularity of 5-200 $\mu \mathrm{m}$. The carrier capacity of the carrier gas can be continuously improved by increasing the carrier gas flowrate from $4.5 / \mathrm{min}$ to $6 \mathrm{~L} / \mathrm{min}$ or even higher. However, this will 


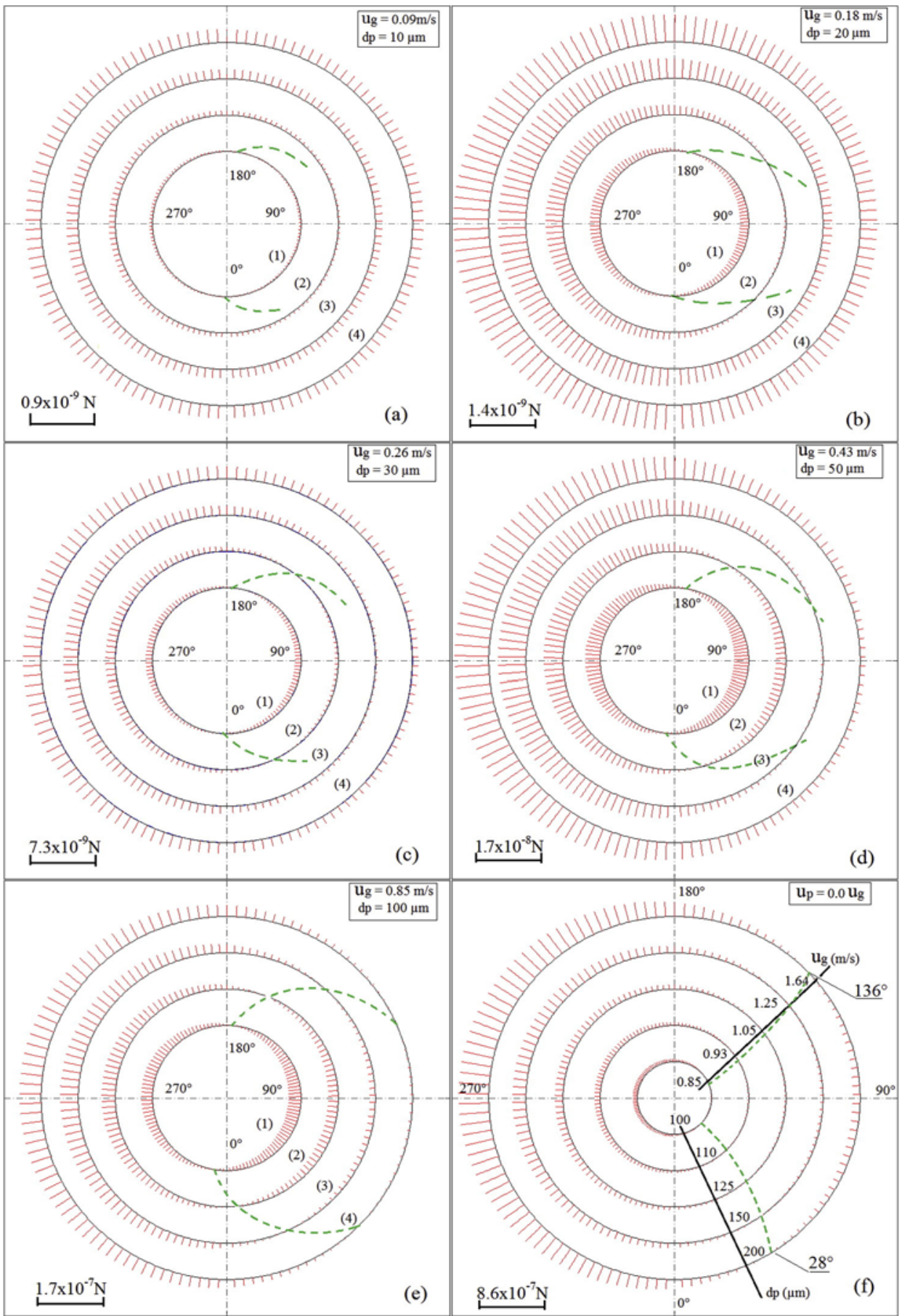

Fig. 20. Tangential force on particles in function of alpha and diameter. (For interpretation of the references to colors in this figure, the reader is referred to the web version of this article.)

also cause a change in the entering state of particles as well as the change in particle trajectories (Fig. 9) in which the impact state of particles may also be affected. Therefore, adjustment in operating parameters (current intensity, plasma gas flowrate, spraying distance ...) is necessary for keeping particles in proper impacting state, for example, with an injection angle, particles can be well prevented from overcrossing the plasma core region when the carrier gas is increased.

According to Fig. 21, with a flowrate of $3 \mathrm{~L} / \mathrm{min}$, particles bigger than $75 \mu \mathrm{m}$ are unable to be completely transported through the transition region and may station down. These stationary powders may then aggregate to cluster or even to slug as mentioned in Figs. 10 and 12. Undoubtedly, the existence of cluster or slug in the carrier tube will cause a reduction in effective cross-section $\left(d_{c}\right)$ shown in Fig. 22. As displayed in Figs. 5-8 and 11, cycles with different durations exist in in-flight particle steam and in powder behavior which mainly originates from the cyclical variation of an effective cross-section. Fig. 22 is proposed to explain the source of such cyclical variation with an effective cross-section indicated by the percentage decreasing from $100 \%$ to $59 \%$ from ( $c 1$ ) to (c6). And $d_{e}$ in millimeter implies the equivalent diameter which is calculated as the diameter of the circle equalized from the effective cross-section. The equivalent diameter decreases from $4 \mathrm{~mm}$ to $3.1 \mathrm{~mm}$ when the effective cross-section is reduced from $100 \%$ to $59 \%$. As a consequence, the local average velocity of the carrier gas obviously augments as the solid curve $(3 \mathrm{~L} / \mathrm{min})$ in Fig. 23 while the dashed line at $6 \mathrm{~m} / \mathrm{s}$ presents the average velocity of the carrier gas calculated with a flowrate of $4.5 \mathrm{~L} / \mathrm{min}$ for carrying all particles. Due to the 




Fig. 21. Effect of carrier gas flowrate on tangential force at $90^{\circ}$.

enhanced effect of carrier velocity from the decrease of the effective area, more particles are able to be carried out of the transition region. That means all particles with sizes of 5-200 $\mu \mathrm{m}$ start to be completely carried with the carrier gas of $3 \mathrm{~L} / \mathrm{min}$ if the effective cross-section is reduced to $66 \%$ ( $d_{e}=3.35 \mathrm{~mm}$ ). The decreased course of the equivalent diameter can be considered as the growing stage of the slug. Similarly, the breaking stage can be defined as the increase course of the equivalent diameter, as shown in Fig. 23. The growing stage is always followed by a breaking stage when the equivalent diameter is smaller than $3.35 \mathrm{~mm}$. Another point that should be noted is that the growing rate of slug will gradually decrease till zero when the equivalent diameter reduces from $4 \mathrm{~mm}$ to $3.35 \mathrm{~mm}$. There is an intermediate stage as 'maturity' between growing stage and breaking stage (where $d_{e}$ is very close to $3.35 \mathrm{~mm}$ ) in which the slug stops growing but the breaking has not yet commenced (Fig. 24).

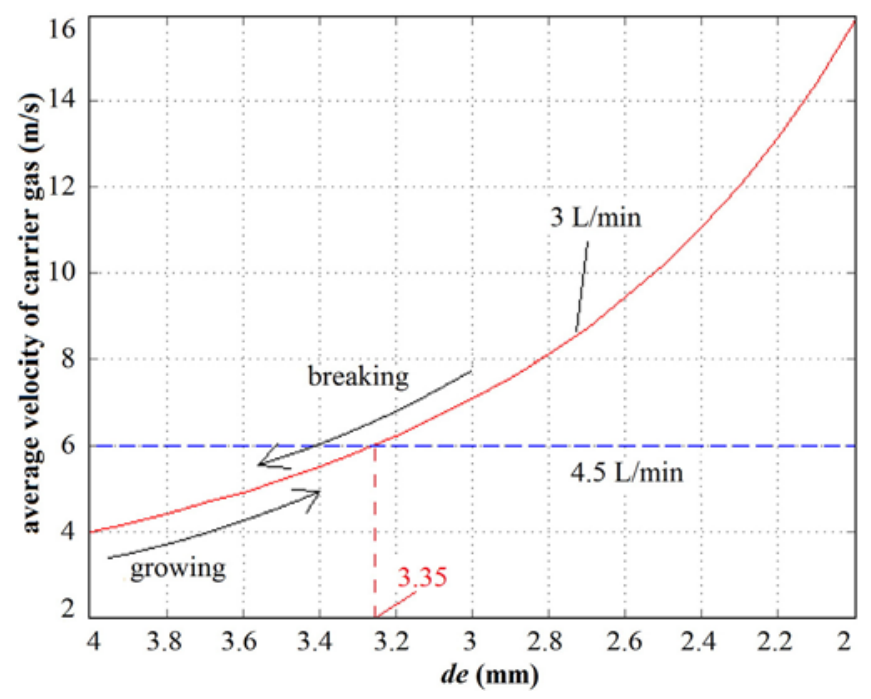

Fig. 23. Effect of variation of the equivalent diameter on carrier velocity.

As displayed in Fig. 24, due to gravity, heavy particles subside down to the wall region (boundary region) and travel along the inner wall as indicated in Fig. 24(A). At a certain instant, some particles start settling and accumulating at the lower edge of the transition region mentioned in Fig. 20 as shown in subgraph (B). The slug continuously grows till 'maturity' (from (C) to (D)) while the equivalent diameter decreases close to the special value (3.35 $\mathrm{mm}$ as mentioned above). Subgraph (E) shows the breaking stage of the slug in which part of the slug has been blown up and atomized as 'dust storm' of particles to cause 'powder flooding' (powder overcharge). The rest of the part is absorbed by a newborn slug existing just behind the breaking slug as shown in (E) of Fig. 24. As explained in Section 3.1, the 'powder flooding' will cause a serious problem in in-flight particle characteristic, mainly at low temperature. And the coating structure is significantly affected by the 'powder flooding', e.g. presence of three layers. Thus, a good understanding on the 'powder flooding' cycle promotes a good control of coating property. Unfortunately, until today there is no public report focusing on this issue, especially for thermal spraying application.

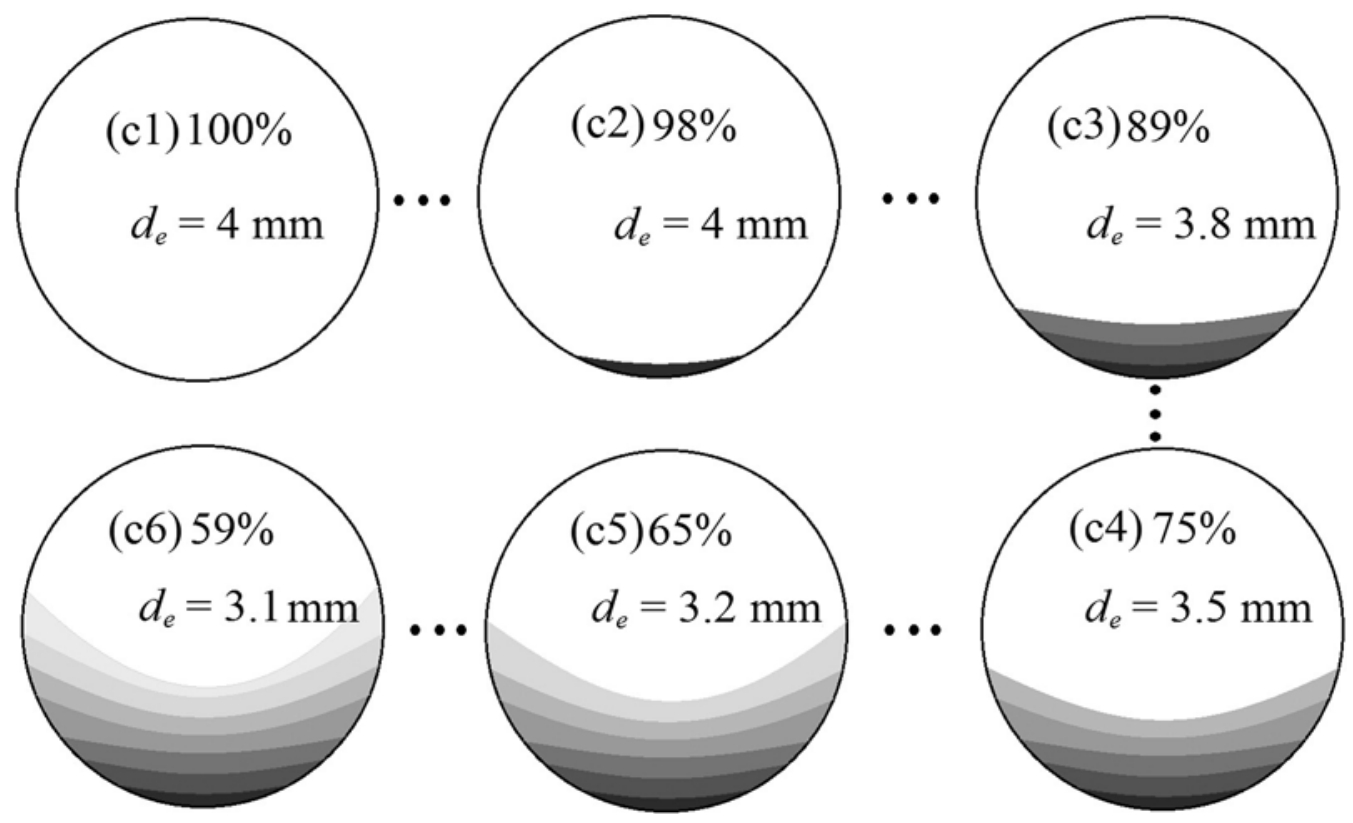

Fig. 22. Variation of effective cross-section of the carrier tube. 

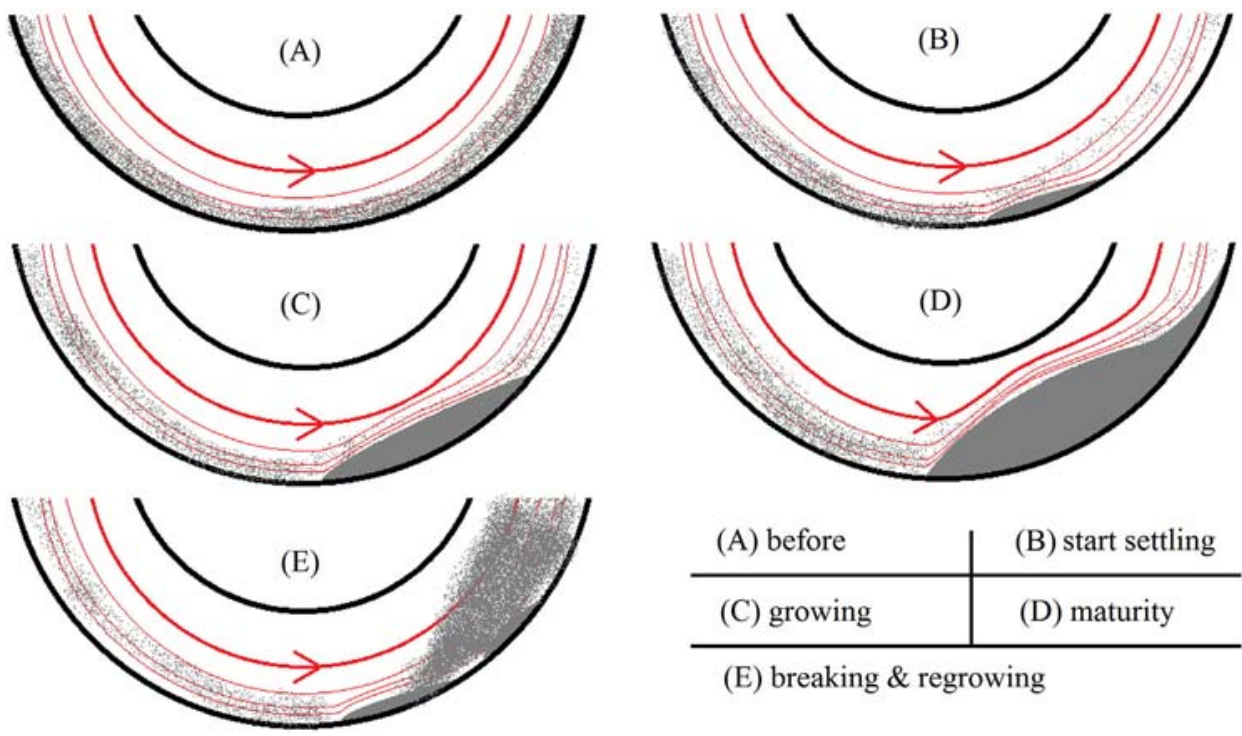

\begin{tabular}{l|l} 
(A) before & (B) start settling \\
\hline (C) growing & (D) maturity \\
\hline
\end{tabular}

(E) breaking \& regrowing

Fig. 24. Demonstration of the growing and breaking of a slug

\subsubsection{Instability description}

According to this work, an empirical equation is proposed to describe the growing stage and breaking stage of the slug. As an indirect method, the 'powder flooding' can be foreseen from the breaking stage. At a bend/elbow, the chance to have a slug and the existence time of such a slug are significantly dominated by powder feeding rate $\left(R_{p}\right)$ and coarse powder fraction $\left(D_{s}\right.$, e.g. $\left.>100 \mu \mathrm{m}\right)$ and diameter of pipe bend $\left(d_{b}\right)$ and equivalent diameter of cross-section $\left(d_{e}\right)$ and carrier gas flowrate $\left(f_{g}\right)$ and the equivalent friction coefficient $\left(C_{f}\right)$ and also the difference of density between carrier gas and powder $\left(\lambda=\rho_{p} / \rho_{g}\right)$. As a synthesis of these variables, an equation is presumed as:

$R=k D_{s} R_{p}-R_{l}$

where $R$ is the mass change rate of slug, $g \cdot \mathrm{s}^{-1} ; k$ is the empirical coefficients estimated as $k=m C_{f} \lambda d_{e} / d_{b}$ with a value of 0.07 for $m ; R_{l}$ is the loss rate of slug mass on the surface, calculated as the product of $4 n \rho_{p} A f_{g} /\left(\pi d_{e}^{2}\right)$ with $A$ representing the windward surface of slug with a value of about $5 \times 10^{-6} \mathrm{~m}^{2}$ and $n$ signifying the erosion coefficient with a value of 0.1 .

The first term at the right side of Eq. (4) presents the growth rate of the slug while the second term presents the decreased rate of slug due to the erosion from the carrier gas. With this equation, the growing and breaking of slug can be easily understood. During the growing state, the growth rate is significantly bigger than the erosion rate in which particles will be continuously captured by the slug. Meanwhile, the erosion rate increases due to the decrease of the equivalent diameter of the cross-section. The mass change rate of slug decreases toward zero during the growing stage. At a certain instant, equilibrium is achieved between growth rate and erosion rate in which the amount of particles lost is the same as that of the particles gained. This stage thus is called the maturity stage. In the breaking stage, due to the break effect, the slug loses a lot of particles in a short course that leads the equivalent diameter of effective cross-section to climb up toward $4 \mathrm{~mm}$ from the special value (e.g., $3.35 \mathrm{~mm}$ ) to a point located between $3.35 \mathrm{~mm}$ and $4 \mathrm{~mm}$. The erosion rate is obviously bigger than the growth rate which gives a negative value of $R$. Therefore, in order to describe the periodic variation of the mass change rate of slug, the equivalent diameter can be written in function of time $t$ :

$d_{e}=d_{0}-\Delta d+\Delta d \cos (a t+b)$ where $d_{0}$ denotes the inner diameter of the carrier tube; $\Delta d$ denotes the variation magnitude of the equivalent diameter with a value of about 0.33 ; and $a$, and $b$ are the coefficients determining the phase of $d_{e}$.

Due to the existence of dilute phase and dense phase [10,11], the real value of variables in Eq. (5) may deviate far from the given value. By considering the existence of multi-bends, the variation of in-flight particle stream is composed of several waves depicted by Eqs. (4) and (5) with different phases and magnitudes. For example, supposing that all variables mentioned in Eqs. (4) and (5) are always the same for slugs at each bend, the variation of particle stream presented as 'LF' in Fig. 6 can be predicted from the total mass change rate of slugs with value provided in Table 2. As shown in Fig. 25, star-dash curve presents the calculated mass change rate of four slugs $\left(R_{-} 4\right)$; plus-dash curve shows the calculated mass change rate of three slugs $\left(R_{-} 3\right)$; circledash curve displays the mass change rate of two slugs $\left(R \_2\right)$; and the solid curve accompanied by void triangles presents the variation of width of in-flight particle stream. In the first $7 \mathrm{~s}$, the tendency of ' $R \_2$ ' coincides well with the variation of 'width' that means in this period only two slugs are formed. Between the 7th second and the 26th second, ' $R \_3$ ' turns to coincide with the variation of 'width' which indicates the existence of three slugs. Then from the 26th second to the 37th second, four slugs can be produced.

Although it is liable to describe slug behavior with these equations, several shortages may be unavoidable. When several bends exist along the carrier tube, all variables mentioned in Eq. (4) can be unavoidably different. Therefore in-flight particle stream will be decided by the multi-effect of all these bends which is unstable and impossible to precisely predict with these equations. Moreover, in different flow systems, e.g. different powders, or a change in position of powder feeder, or even a change in the connection between powder feeder and injector can result in a quite different particle behavior. Thus the necessary modification should be carried out according to the new situation. While, there is no doubt that these equations contribute to the understanding of the instability of powder feeding.

Table 2

Value of variables $a$ and $b$ in Eq. (5).

\begin{tabular}{lll}
\hline & $a$ & $b$ \\
\hline Slug no. 1 & 0.4 & 4 \\
Slug no. 2 & 0.5 & 5 \\
Slug no. 3 & 0.6 & 6 \\
Slug no. 4 & 0.7 & 7
\end{tabular}




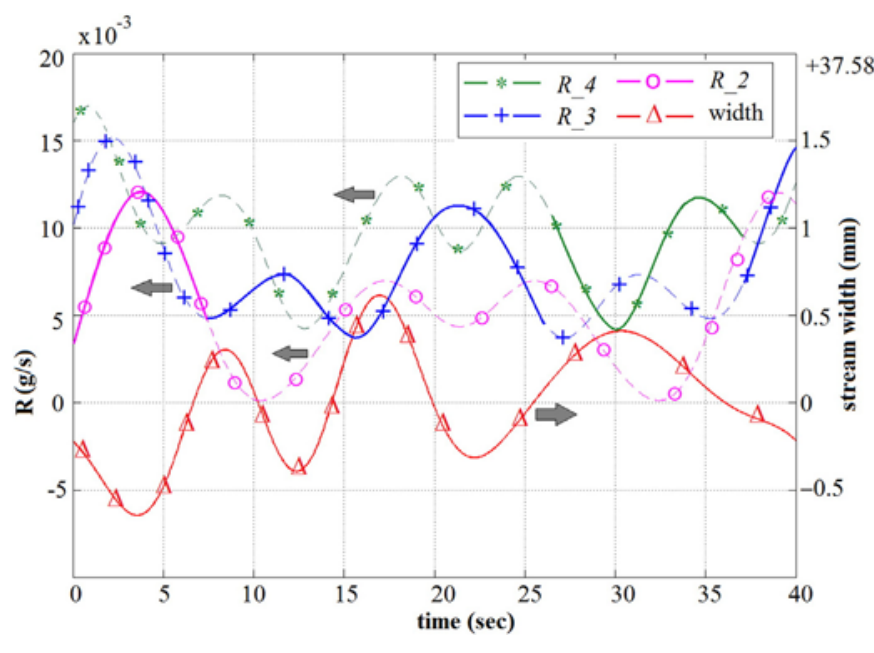

Fig. 25. An example of the relation between mass change rate of slug and stream.

\section{Conclusions}

In-flight particle streams and powder feeding were watched through a video camera with $30 \mathrm{fps}$ in this paper. The streams were found to be very unstable both in horizontal view and vertical view with high frequency fluctuation and low frequency fluctuation. Subsidence of powder close to the lower inner wall of the carrier tube was found downslope with very high frequency and low frequency similar to that found in in-flight particle streams. Slug of settled powder was detected and part of the slug can be swirled into the carrier gas from the slug surface with low velocity following the feeding direction. As an effect of unstable powder feeding, the coating presented a three layer structure: a lower layer close to the substrate surface with an average porosity ratio of 3.3\%, mid layer including a large amount of pores with an average porosity ratio of $7.8 \%$ and upper layer which is the densest with an average porosity ratio of $2.2 \%$.

Particle behavior in the carrier tube was also studied through numerical calculation based on force equilibrium between particles and carrier gas and carrier tube. The Stokes number was calculated to estimate the response of particles to the change of carrier gas motion. When carried through a level straight tube, in the boundary region, fine particles can quickly arrive at a stable state while coarse particles need about $1 \mathrm{~s}$ to achieve a sub-stable state. A minimal length of carrier tube for stabilizing powder feeding is about $1.4 \mathrm{~m}$. When carried through tube with bends/elbows, the transition region was found to prevent particles from transporting with two edges. The lower edge of the transition region moves toward $0^{\circ}$ and the upper edge moves toward $180^{\circ}$ when increasing the particle diameter.

According to calculation, the carrier gas with a flowrate of $4.5 \mathrm{~L} / \mathrm{min}$ can well carry up powder with a granularity of $5-200 \mu \mathrm{m}$. The equivalent diameter was estimated from the reduced cross-section to decide when the breaking stage of the slug commences. By turning from growing stage to breaking stage, a cycle was formed as the period found in inflight particle streams. An equation was proposed to describe slug behavior in the form of mass change rate. It is easy to understand slug behavior with this equation: in growing state, the growth rate of slug is bigger than loss rate (or erosion rate); in maturity instant, the growth rate equals loss rate; in breaking stage, the loss rate is bigger than growth rate. However, this equation was limited by the carrier tube state and by flow system and by the quantity of slugs.

\section{Acknowledgments}

The authors would like to express great thanks to Günter Roth for the technical support. The authors also would like to acknowledge the Deutsches Zentrum für Luft-und Raumfahrt (DLR)/Deutscher Akademischer Austauschdienst (DAAD) Research Fellowship Program for Postdocs with grant number 50019752.

\section{References}

[1] J.F. Bisson, B. Gauthier, C. Moreau, Effect of plasma fluctuations on in-flight particle parameters, J. Therm. Spray Technol. 12 (2003) 38-43.

[2] R.R. Kieschke, K.A. Roberts, T.W. Clyne, Instabilities in the vacuum plasma spraying process, Surf. Coat. Technol. 46 (1991) 25-38.

[3] J.F. Coudert, V. Rat, The role of torch instabilities in the suspension plasma spraying process, Surf. Coat. Technol. 205 (2010) 494-953.

[4] P. Fauchais, J. Coudert, M. Vardelle, Transient phenomena in plasma torches and in plasma sprayed coating generation, J. Phys. IV France 7 (1997) c4-187-198.

[5] E. Meillot, G. Balmigere, Plasma spraying modeling: particle injection in a timefluctuating plasma jet, Surf. Coat. Technol. 202 (2008) 4465-4469.

[6] M. Vardelle, A. Vardelle, P. Fauchais, Spray parameters and particle behavior relationships during plasma spraying. J. Therm. Spray Technol. 2 (1993) 79-92.

[7] I. Kriba, A. Djebaili, Numerical study of melted particles crush metallic substrates and the interaction between particles and a plasma beam in the thermal projection process, Appl. Surf. Sci. 255 (2009) 5637-5640.

[8] T. Zhang, D.T. Gawne, B. Liu, Computer modelling of the influence of process parameters on the heating and acceleration of particles during plasma spraying, Surf. Coat Technol. 132 (2000) 233-243.

[9] M. Vardelle, A. Vardelle, P. Fauchais, K.I. Li, B. Dussoubs, N.J. Themelis, Controlling particle injection in plasma spraying, J. Therm. Spray Technol. 10 (2001) 267-284

[10] R. Pan, B. Mi, P.W. Wypych, Pneumatic conveying characteristics of fine and granular bulk solids, KONA 12 (1994) 77-84.

[11] E. Helland, R. Occelli, L. Tadrist, Computational study of fluctuating motions and cluster structures in gas-particles flows, Int. J. Multiphase Flow 28 (2002) 199-223.

[12] R. Röhrig, S. Jakirlic, C. Tropea, Comparative computational study of turbulent flow in a $90^{\circ}$ pipe flow, Int. J. Heat Fluid Flow (on line) (2015) Available at: http://dx. doi.org/10.1016/j.ijheatfluidflow.2015.07.011.

[13] S. Fokeer, S. Kingman, I. Lowndes, A. Reynolds, Characterisation of the cross sectional particle concentration distribution in horizontal dilute flow conveying-a review, Chem. Eng. Process. 43 (2004) 677-691.

[14] A. Yilmaz, E.K. Levy, Formation and dispersion of ropes in pneumatic conveying, Powder Technol. 114 (2001) 168-185.

[15] H. Akilli, E.K. Levy, B. Sahin, Gas-solid flow behavior in a horizontal pipe after a $90^{\circ}$ vertical-to-horizontal elbow, Powder Technol. 116 (2001) 43-52.

[16] S. Laín, M. Sommerfeld, B. Quintero, Numerical simulation of secondary flow in pneumatic conveying of solid particles in a horizontal circular pipe, Braz. J. Chem. Eng. 26 (2009) 583-594

[17] E. Helland, R. Occelli, L. Tadrist, Numerical study of cluster formation in a gasparticle circulating fluidized bed, Powder Technol. 110 (2000) 210-221.

[18] Y. Pan, S. Banerjee, Numerical simulation of particle interactions with wall turbulence, Phys. Fluids 8 (1996) 2733-2755.

[19] I. Tabernero, A. Lamikiz, E. Ukar, L.N. López de Lacalle, C. Angulo, G. Urbikain, Numerical simulation and experimental validation of powder flux distribution in coaxial laser cladding, J. Mater. Process. Technol. 210 (2010) 2125-2134.

[20] M. Sommerfeld, Analysis of collision effects for turbulent gas-particle flow in a horizontal channel: part I. Particle transport, Int. J. Multiphase Flow 29 (2003) 675-699.

[21] H. Bounaouara, H. Ettouati, H. Ben Ticha, A. Mhimid, J.C. Sautet, Numerical simulation of gas-particles two phase flow in pipe of complex geometry: pneumatic conveying of olive cake particles toward a dust burner, Int. J. Heat Technol. 33 (2015) 99-106.

[22] K. Ramachandran, V. Selvarajan, Trajectory and temperature history of the particles of different sizes and their injection velocities in a thermal plasma, Comput. Mater. Sci. 6 (1996) 81-91.

[23] H. Zhou, G. Flamant, D. Gauthier, J. Lu, Lagrangian approach for simulating the gasparticle flow structure in a circulating fluidized bed riser, Int. J. Multiphase Flow 28 (2002) 1801-1821.

[24] Y.M. El-Sherbiny, A.T. Hasouna, W.Y. Ali, Friction coefficient of rubber sliding against flooring materials, J. Eng. Appl. Sci. 7 (2012) 121-126.

[25] Z. Duan, J. Heberlein, Arc instabilities in a plasma spray torch, J. Therm. Spray Technol. 11 (2002) 44-51.

[26] X.C. Zhang, B.S. Xu, Y.X. Wu, F.Z. Xuan, S.T. Tu, Porosity, mechanical properties, residual stresses of supersonic plasma-sprayed Ni-based alloy coatings prepared at different powder feed rates, Appl. Surf. Sci. 254 (2008) 3879-3889.

[27] H.B. Xiong, L.L. Heng, S. Sampath, R.L. Williamson, J.R. Fincke, Three-dimensional simulation of plasma spray: effects of carrier gas flow and particle injection on plasma jet and entrained particle behavior, Int. J. Heat Mass Transf. 47 (2004) 5189-5200.

[28] C.T. Crow, R.A. Gore, Modulation of turbulence by a dispersed phase, J. Fluid. Eng Trans. ASME 113 (1991) 304-307. 